\title{
INSTITUTE
}

\section{MAINSTREAMING CLIMATE ADAPTATION PLANNING AND ACTION INTO HEALTH SYSTEMS IN FIJI, GHANA, AND BENIN}

\section{EXECUTIVE SUMMARY}

\section{Highlights}

While the world's attention is on the global COVID-19 pandemic, climate change is also impacting human health and straining heavily burdened health services everywhere.

- Recognition of the linkages between climate change and health systems, such as shifts in vector-borne diseases and decreased access to services, is growing, yet many countries are still struggling both to mainstream, or integrate, climate adaptation into their health plans and to implement activities on the ground.

- This paper shares case studies from Fiji, Ghana, and Benin, three countries making progress with mainstreaming climate change adaptation into planning and implementation in health systems.

- These countries are instituting well-informed policies and plans, strengthening existing health systems, implementing and then expanding pilot projects, and demonstrating political leadership.

- However, challenges remain, including insufficient understanding and inadequate communication of linkages between climate change and health, poor data access and availability, and limited funding.

- Recommendations that emerge from these case studies include increasing human and financial resources; taking critical "no-regrets" actions now, such as increasing training of medical staff; funding and expanding successful pilot studies; establishing policy frameworks and collaboration mechanisms

\section{CONTENTS}

Executive Summary 1

1. Purpose and Scope of This Working Paper ......... 4

2. Methodology ....................................... 4

3. Climate Change and Human Health:

A Growing Sense of Urgency .... 6

4. Experiences with Mainstreaming

Adaptation into National Health Systems 10

5. Lessons Learned on Mainstreaming Adaptation in Fiji, Ghana, and Benin ......................... 19

6. Recommendations ............................... 21

7. Conclusion ...................................... 22

Appendix A ....................................23

Endnotes........................................... 24

References .......................................... 24

Acknowledgments................................28

Working Papers contain preliminary research, analysis, findings, and recommendations. They are circulated to stimulate timely discussion and critical feedback, and to influence ongoing debate on emerging issues. Working papers may eventually be published in another form and their content may be revised.

Suggested Citation: Tye, S., and J. Waslander. 2021. "Mainstreaming Climate Adaptation Planning and Action into Health Systems in Fiji, Ghana, and Benin." Working Paper. Washington, DC: World Resources Institute. Available online at https://doi.org/10.46830/wriwp.19.00119. 
to mainstream adaptation; adopting a cross-sectoral approach; and linking health officials and adaptation planners.

\section{The Global Pandemic Highlights the Need to Plan for Climate Risks in Health Systems}

\section{The COVID-19 pandemic has highlighted the vulnerability of health systems. Without making} changes to improve the robustness and resilience of health systems, these systems will be even less prepared to withstand the bigger shocks and stressors brought on by climate change. COVID-19 has laid bare the fact that few health systems are currently able to manage unexpected shocks well and that, as with climate change, the effects are disproportionally felt by the most vulnerable. Climate impacts are already undermining human health, threatening lives and health services everywhere. This upward trend is expected to intensify as global temperatures rise-which, among other problems, could help zoonotic diseases such as COVID-19 proliferate. The current crisis underlines the urgency with which countries must prepare for even greater challenges.

\section{Health risks linked to climate change are many and varied. These include shifts in the geographical range and incidence of vector-borne diseases and foodborne illnesses, and increases in physical injuries, mental stress, and food insecurity and malnutrition. Climate events also impair critical health infrastructure, making it harder for people to access health care. Climate impacts are especially being felt by the most vulnerable, including people living in poverty, those who are ill or disabled, women, children, and the elderly.}

\section{This paper was largely drafted prior to the} outbreak of COVID-19 but has benefited from our observation of the global response to the pandemic. Governments and organizations around the world have focused on finding ways to "build back better," and initiatives have been launched to define and map out plans for achieving this goal. Leaders everywhere are recognizing that they will need to spend trillions of dollars responding to the direct and indirect effects of the novel coronavirus, such as widespread unemployment and economic crises, food security issues, and other challenges. But continuing to rebuild key systemsincluding in the health sector-in ways that do not help build resilience and that exacerbate inequality is unwise and shortsighted. Countries must instead build back their economies-including their health systems-better by preparing for a range of future shocks, including pandemics and climate change impacts.

This paper examines three countries-Fiji, Ghana, and Benin-that are currently working to make their health systems more resilient to climate change impacts. It explores the context, enabling factors, and challenges in each country, and identifies lessons learned and successful strategies that these countries have in common. It suggests ways in which health systems can be made more resilient by mainstreaming climate adaptation into health care and moving from planning to implementation. Many of the actions described could also apply to building resilience to infectious disease outbreaks and other health care challenges.

\section{About This Working Paper}

World Resources Institute (WRI), with support from Germany's Federal Ministry for Economic Cooperation and Development as a contribution to the NDC Partnership, is seeking to provide guidance to NDC Partnership member countries facing challenges mainstreaming adaptation across sectors and from the national to the local level. This paper is part of a series of case studies that apply WRI's framework for successful mainstreaming (Mogelgaard et al. 2018) and identify elements essential for success. The series features the following:

From Planning to Action: Mainstreaming Climate Change Adaptation into Development (Mogelgaard et al. 2018), which conducted a global analysis to identify factors that enable mainstreaming and implementation of adaptation activities

Mainstreaming Adaptation in Action: Case Studies from Two States in India (Dinshaw et al. 2018), which examines mainstreaming at the state level in the livestock and forestry sectors

Assessment of the Limits, Challenges, and Opportunities for Adaptation Mainstreaming in Brazilian Cities (Speranza et al. 2018), an internal report to the government of Brazil focused on mainstreaming from the national to the city level and the challenges of implementation 
Mainstreaming Climate Change Adaptation in Kenya: Lessons from Makueni and Wajir Counties (Chaudhury et al. 2020), which describes two local governments emerging as leaders in planning and implementing mainstreamed adaptation actions

Building Coastal Resilience in Bangladesh, the Philippines, and Colombia: Country Experiences with Mainstreaming Climate Adaptation (Tye et al. 2020), a paper that examines three cases with on-the-ground actions to narrow the "implementation gap" between planning and action

\section{Key Findings}

Linking climate adaptation and health policies is in high demand by countries, but effective action is lagging. More than half of the developing-country members of the NDC Partnership-a global coalition that helps countries find the technical support they need to draft, implement, and enhance their national climate commitments-have requested support through the partnership to strengthen their health systems' resilience against the effects of climate change. However, many developing countries have made limited progress in developing plans, policies, and specific projects to address this complex issue.

Many countries' health systems were already heavily strained even before the COVID-19 pandemic, with limited ability to address climate change impacts. The combination of COVID-19 and climate impacts will stress these systems even further.

Case studies of Fiji, Ghana, and Benin demonstrate how climate adaptation can be mainstreamed into health policies, plans, and pilot projects, setting the stage for broader implementation of solutions. These countries are finding that strengthening health sector institutions, infrastructure, supply chains, and staff training is necessary to both build a more resilient foundation for the health sector and be in a better position to tackle climate change impacts and other types of shocks.

Pilot projects can demonstrate how mainstreaming climate adaptation into health policies can lead to broader, more comprehensive responses. In two of the three case study countries, Ghana and Benin, pilots helped to inform policies and plans, and wider implementation. However, lessons learned from such projects must lead to implementing and scaling up climate-resilient health policies if they are to be effective long-term.

Political champions who understand the synergies between health and climate can play a crucial role in demonstrating leadership and providing guidance to develop and implement climateresilient health policies.

Mechanisms like interagency climate committees are important for engaging key stakeholders in mainstreaming climate adaptation into the health sector. Improved coordination will help in adding adaptation to health sector plans and policies and in closing the implementation gap.

Challenges exist around translating and communicating technical terminology related to climate change into health policies. Limited access to and availability of data and funding to make the case for climate-related health risks present another barrier.

\section{Recommendations}

Enough information on climate-sensitive health risks exists to adopt critical no-regrets adaptation measures now to strengthen health care systems. Such measures need to be context-specific yet could incorporate best practices that have proved helpful elsewhere, such as training staff in vector-borne diseases and improving hospital infrastructure. Action should be taken immediately despite the need for better data and improved access to data in the case study countries and worldwide.

Policymakers can seize on the political moment created by the global pandemic to strengthen their countries' abilities to respond to a range of other shocks and stressors-including the linked challenges of human health and climate change. The COVID-19 pandemic is shining a spotlight on the importance of robust and resilient health care systems. Increasing human capacity and financial resources is paramount for ensuring that effective measures are taken in time to better manage rapidly mounting climate-related risks to health. 
Governments should establish policy frameworks and collaboration mechanisms to provide needed guidance and support to mainstream climate adaptation into the health sector. Formal frameworks and legislation help ensure that resources are dedicated to this issue.

Funders, including governments, should encourage and finance health projects and use lessons from these experiences to inform climate resilience planning in health sector plans and policies. As illustrated by the Fiji and Benin case studies, pilot projects can serve as a basis to expand broader national efforts and lead to cross-sectoral learning experiences.

Ministries of Health and adaptation planners should jointly design and implement health plans and policies that mainstream climate adaptation and demonstrate their feasibility through onthe-ground projects. Greater collaboration between these two areas of expertise can strengthen policies and implementation plans.

A cross-cutting, cross-sectoral approach that increases political will by engaging adaptation champions and key stakeholders, including subnational public and private actors, is needed to make health systems more resilient to climate change. Climate action advocates within and outside of the health sector are needed to galvanize broad support for strengthening health systems.

\section{PURPOSE AND SCOPE OFTHIS WORKING PAPER}

After describing the methodology used to identify the Fiji, Ghana, and Benin case studies, the paper dives into each country's climate context, enabling factors, and challenges to mainstreaming and implementing adaptation in public health. Where possible, the sections detail concrete adaptation measures and benefits. Following the case studies, the authors discuss lessons learned and recommendations to mainstream climate adaptation and build climate resilience in the health sector.

The main audience for this paper includes government officials at both the national and subnational level who are responsible for formulating and implementing nationally determined contributions (NDCs) and National
Adaptation Plans (NAPs), which aim to mainstream adaptation across sectors and levels of government. Public health officials and other actors in the health sector, including health care professionals and researchers, as well as institutions like hospitals and medical research centers, form part of this primary audience. In addition, organizations and knowledge institutions supporting the implementation of adaptation activities could use the country experiences mentioned as examples to inform their own work. This working paper may also be of use to private businesses, civil society organizations, and groups most affected by climate impacts (including people living in poverty and facing marginalization). The paper may also serve the needs of funding entities and donors seeking examples of good practice.

\section{METHODOLOGY}

This paper is the product of an iterative process to better understand the perspectives and challenges faced by countries working to build resilience to climate change impacts. It began when WRI and NAP Global Network (NAP-GN) convened three Informal Dialogues on Adaptation: the first on the sidelines of the United Nations Framework Convention on Climate Change (UNFCCC) 24th Conference of the Parties (COP24) in December 2018, the second at the UNFCCC Bonn Intersessional in June 2019, and the third during the UNFCCC COP25 in December 2019. These informal dialogues and follow-up discussions revealed that governments understand well the importance of mainstreaming climate adaptation into national development plans and sectoral policies, and often use National Adaptation Plan processes to focus such efforts. They are also aware that a variety of resources and initiatives exist to support their efforts. Nevertheless, most countries acknowledged that moving from adaptation planning to on-the-ground implementation continues to be a critical challenge.

Mainstreaming adaptation was consistently raised during these dialogues as an important topic for NDC Partnership member countries, as further evidenced by the fact that it was included in 43 out of 73 NDCs from these countries (as of November 2019). Mainstreaming also appears frequently in countries' Request for Support Letters to the NDC Partnership, which then matches country requests with knowledge institutions and implementing agencies that can provide the needed support. The findings in this paper could help fill some of the gaps discussed in countries' request letters. 
The authors took several steps to identify which specific topics related to mainstreaming adaptation were most relevant to NDC Partnership member countries, and to pinpoint countries whose experiences could be shared through WRI's series of papers on mainstreaming, including this one. These steps include the following:

1. Keyword searches for adaptation activities described in The GCF's Approach to Adaptation: Analysis and Implications for the Fund (WRI 2018) were conducted to identify an initial set of 20 topics (e.g., agriculture, ecosystems, health).

2. Using the NDC Partnership Knowledge Portal (https://ndcpartnership.org/knowledge-portal), we examined the NDCs of all 73 NDC Partnership member countries in Africa, Asia, Latin America and the Caribbean, and the Pacific (submitted as of November 2019) to identify which topical keywords from the Green Climate Fund (GCF) categories related to adaptation mainstreaming were mentioned most frequently. The most-referenced topics were agriculture (by 55 countries), disaster risk reduction (52), watersheds and rivers (45), ecosystems (44), and human health (36) (see Figure 1).

3. We employed the NDC Partnership's internal "kNook" database to assess which NDC Partnership countries requested mainstreaming adaptation support between 2016 and 2019 (i.e., since the founding of the NDC Partnership). We looked at documents, such as countries' letters requesting support, and identified countries' intentions to mainstream adaptation or their mainstreaming initiatives underway.

4. We researched articles and publications, including NAP-GN resources and the NDC Partnership Good Practice Database, illustrating how countries have narrowed or closed the "implementation gap" between planning and action for the topics identified. A variety of examples were found; disaster risk reduction and human health were the topics addressed by at least three countries each, leading WRI to focus on these two areas in its mainstreaming case study series.

5. NDC Partnership member countries Fiji, Ghana, and Benin were chosen as case study countries for health because these three countries are part of the small group for which documented evidence of implementation was found, and they represent experiences from a low-income country (Benin) and low-to-middle-income countries (Ghana and Fiji). The countries varied in terms of their level of vulnerability
Figure 1 | Most Frequent Mentions of Adaptation Mainstreaming by Topic in NDCs (as of November 2019)

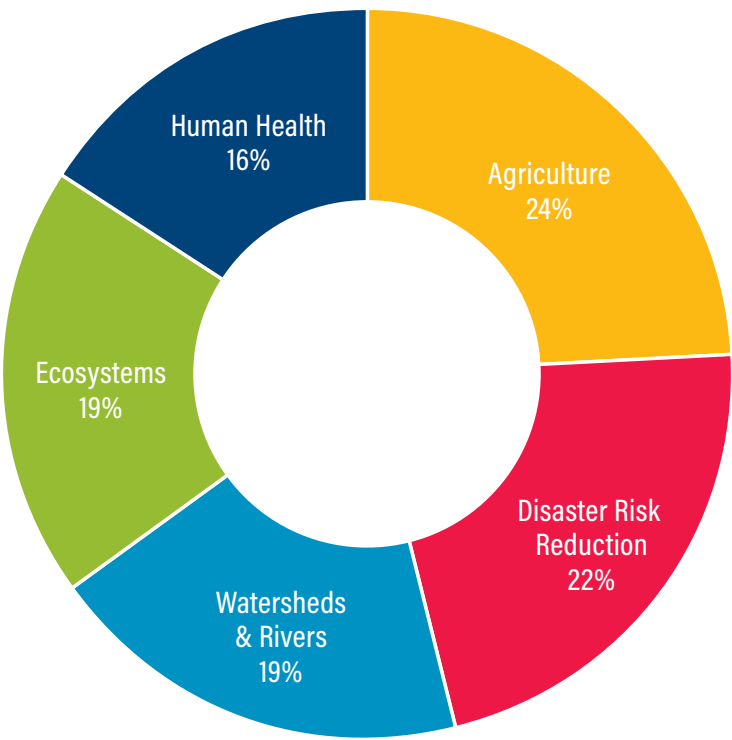

Notes: After our analysis started in November 2019, the NDC Partnership released in March 2020 an assessment of gaps between the country adaptation requests it had received and those being supported through its partners. Of more than 700 output-level requests from 64 countries, the NDC Partnership analysis found just four health-specific requests, of which only two were being supported. NDC stands for nationally determined contribution.

Source: Authors,

and readiness to adapt to climate change, according to their 2018 rankings in Notre Dame's Global Adaptation Initiative (ND-GAIN) Country Index . ${ }^{1}$ Coming in at a ranking of 75, Fiji-with a score of 49.9 out of $100-$ is a moderately vulnerable country out of the 181 countries surveyed; and Ghana-with a rating of 44.3 out of $100-$ is similarly vulnerable. In contrast, Benin is rated 37.8 out of 100 due to its high vulnerability and low level of readiness (NDGAIN 2018). The countries represent a broad range of contexts and experiences, although the sample size of three countries is too small to determine correlation or causation between income level and degree of risk.

Once topics and countries had been identified, the authors reviewed key planning documents, reports, government websites, and online articles (both academic and from news sources) from the case study countries to gather evidence on adaptation mainstreaming and implementation. Authors also analyzed notes from the Informal Dialogues on Adaptation to identify specific member country representatives to interview for this paper. In total, nine in-depth interviews were conducted with experts knowledgeable about mainstreaming 
adaptation and the health sector in the three case study countries. The interviews were based on a semi-structured questionnaire used to probe the mainstreaming process and how the implementation gap had been narrowed or closed (see Appendix A). To more consistently identify the factors that have enabled or hindered mainstreaming, questions were based on the five "gears" outlined in Mogelgaard et al. (2018). The interview protocol permitted other factors beyond the five gears to be identified. Questions were also asked about whether implementation has benefited vulnerable people.

A limitation of this methodology is the small sample size of interviewees, which did not include a full range of perspectives. To help fill this gap, the team shared preliminary findings for discussion and feedback with a small group of climate and health experts, including health professionals, at the World Health Summit held in Berlin, Germany, in October 2019.

This research was not able to evaluate whether the implementation of adaptation actions has built resilience or led to other outcomes; indeed, these countries have yet to finalize the monitoring and evaluation systems that will measure and evaluate outcomes. However, where possible, the paper highlights early indications of the benefits of adaptation interventions, such as improved technical capacity to track and treat diseases exacerbated by climate risks. Due to time and resource limitations, this paper also did not look into counterfactual cases where adaptation actions have not been implemented.

\section{CLIMATE CHANGE AND HUMAN HEALTH: A GROWING SENSE OF URGENCY}

\subsection{Climate Change and Other Shocks Are Already Impacting People's Health and Health Systems}

The COVID-19 pandemic has made clear that health systems around the world must be made more resilient to a range of potential shocks. Among these shocks is climate change, which poses a grave threat to human lives and to global public health, putting already-burdened health care systems-especially in low-income countries-under even greater stress. People living in poverty, whether in the Global South or in wealthier countries like the United States, in many cases still lack adequate access to basic health services. Without support and funding, vulnerable groups of people like the elderly, the sick and chronically ill, children, women, and other marginalized groups-all vulnerable for different reasons-will continue to suffer the most from the impacts of climate change on health (WHO 2018a; Ebi et al. 2019). For example, women and girls are more likely to suffer from climate-related food insecurity and poor mental health compared with men and boys (Dunne 2020).

Health-related risks due to the effects of climate change range from increased likelihood of transmitting vector-borne diseases (like malaria and dengue) and water-borne illnesses, to decreased air quality, as seen in Figure 2 (WHO 2018a; Ebi et al. 2019). The World Health Organization (WHO) estimates that one-sixth of illness and disability suffered globally is due to vectorborne diseases (Campbell-Lendrum et al. 2015). Climate change is redistributing and increasing the optimal habitats for mosquitoes and other pathogens that carry disease-in some cases, bringing infectious diseases into communities that had not encountered them before-and causing epidemics, and overall heightening suffering and countries' burdens of disease (Caminade et al. 2019).

Similarly, hotter temperatures and extreme events (like stronger cyclones and landslides) can cause physical injuries, water contamination, decreased labor productivity, and mental stress. When climate change negatively impacts crop yields and quality, this in turn can lead to greater food insecurity and undernutrition (especially affecting child growth and development; Ebi et al. 2019). Climate change is also linked to migration due to environmental degradation, natural resources instability, and conflict. This can expose people to physical and mental health stressors, exacerbate existing health issues, and lead to poorer living conditions and reduced access to affordable medical care. Climate events can also impair or damage critical health infrastructure systems, making it harder for citizens to access health services.

The rising frequency, intensity, and duration of extreme weather events (e.g., violent storms, droughts, and floods) will disproportionately impact the physical and economic capacities of people and households already struggling with weakened health and chronic disease (e.g., cardiovascular, cerebrovascular, and respiratory diseases). Slow-onset effects of climate change like increasing water stress, decreasing crop yields, and poorer crop nutritional quality also affect health and are predicted to worsen existing health problems (HRC 2018; IPCC 2014). The World Health Organization conservatively projects an 
additional 250,000 deaths per year between 2030 and 2050 due to the global burden of climate change, and also recognizes its effects on the health of hundreds of millions more (WHO 2018a). Every day spent in ill health contributes to heightened mortality and morbidity, increasing countries' disease burdens. The importance of being prepared and able to respond to crises in an agile and inclusive manner to protect lives, livelihoods, and property cannot be overstated.

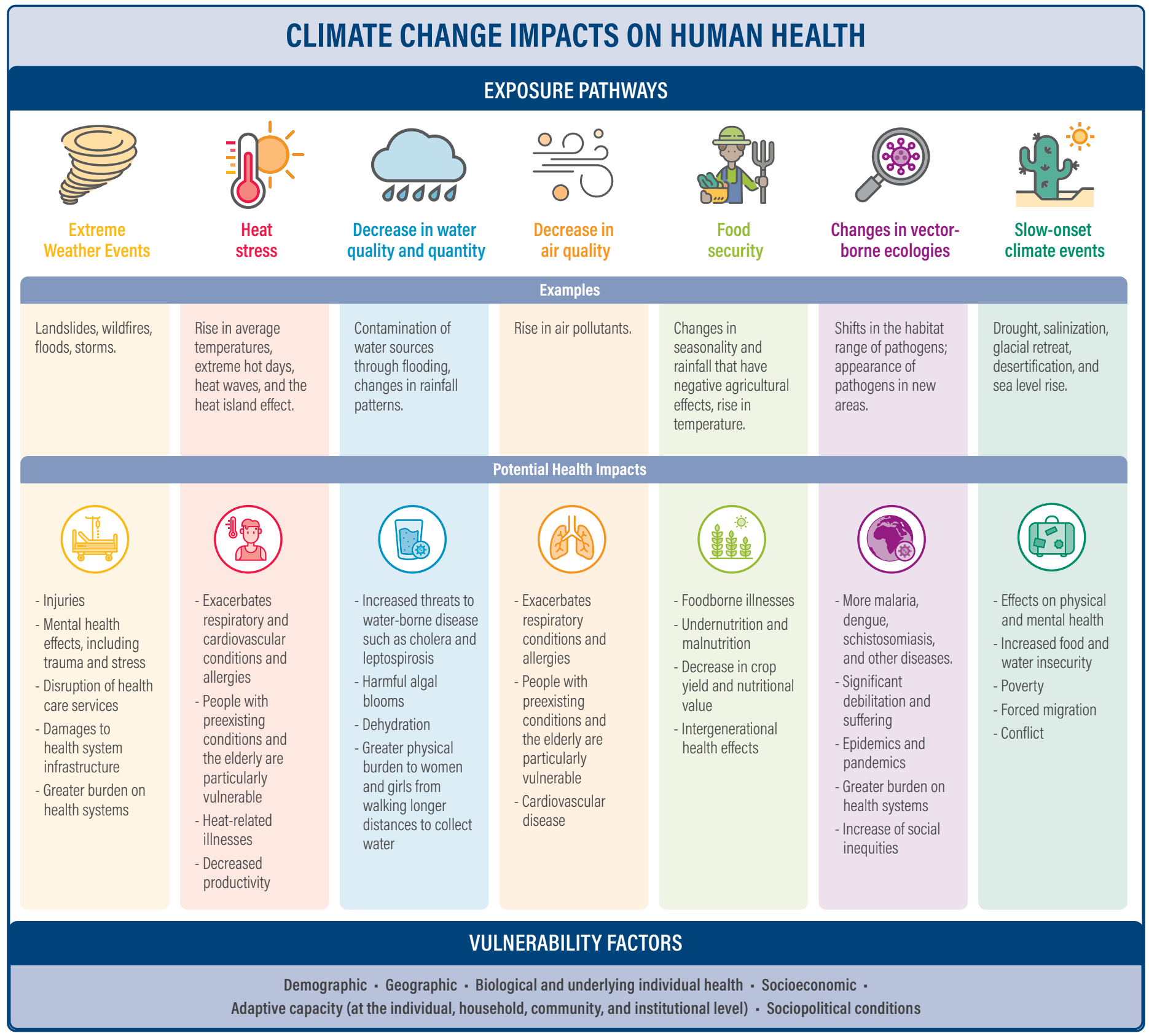

Notes: This infographic is meant to illustrate the main linkages between climate and health and is not exhaustive. Please note that social equities and Disability Adjusted Life Years (DALYs), representing years of life spent in states of less than full health or with disability, can be lost across all exposure pathways.

Source: Adapted from WHO 2021. 


\subsection{Protecting Human Health from Climate Impacts Is Imperative for Countries}

The relationship between health and changing climate conditions is becoming clearer, yet progress on mainstreaming resilience into health systems has been slow, despite being urgently needed (Ebi et al. 2019). Even though human health is a priority in 57 percent of countries' NDCs that have an adaptation component, and close to half of NDCs acknowledge the negative health impacts of climate change, only 0.5 percent of multilateral climate finance has been targeted for health (WHO 2018a; WHO 2019a). Health is a priority sector in the 20 NAPs submitted as of December 2020, covering approximately 10 percent of all adaptation actions mentioned (Savage et al. forthcoming). Many NAPs have not calculated budget requirements for health actions, though nine estimate that these would require $0.1-18.25$ percent of their adaptation budgets (Savage et al. forthcoming).

Despite being a priority, health-specific projects are vastly underrepresented in countries' requests for technical and financial support to the NDC Partnership (NDC Partnership 2020). In the case of the NDC Partnership, just over half of health-climate requests remain unsupported, highlighting a technical services gap among partners, with the WHO playing a central role in finding ways to address this lack of support (Voita and Morton 2020). Likewise, health appears in only 13.5 percent of Green Climate Fund country briefs and programs, with similar rates among its peers, making health the area that showed the greatest divergence and inconsistency between countries' stated needs and funded activities (WRI 2018). Additional research is needed to understand why so few health-related projects are put forward; for example, countries may have difficulty translating concerns (or data) into actionable proposals and calculating what financial resources are needed.

In a global review of over 100 countries, the United Nations (UN) found that fewer than one in five countries is spending enough to implement climate-related health commitments (UN 2019). This gap will be further exacerbated by 2030, when the direct damage costs to health (excluding indirect effects) are expected to be between US $\$ 2$ and $\$ 4$ billion per year (WHO 2018b). Failing to protect health systems or take action to enhance their resilience can erode countries' hard-won development gains, lead to less productive workforces, and aggravate the stress experienced by already heavily burdened health systems.
The COVID-19 pandemic, which has paralyzed entire economies and stretched health systems beyond their capacities in many locations, demonstrates how crucial it is to have robust and resilient health systems. Bridging the gap between policies and their implementation is essential for reducing losses in health systems when (not if) the next crisis arises (Ebi et al. 2019).

\subsection{Mainstreaming Climate Risk Management into Health Systems Enhances Resillience}

To reduce climate change risks and lower vulnerabilities, adaptation must be mainstreamed into health policies and plans. Mainstreaming is the process by which information on climate risks, hazards, and vulnerabilities is integrated into development policies, programs, plans, and projects to make them climate resilient, which often leads to improved development outcomes (Mogelgaard et al. 2018; Gupta and van der Grijp 2010; Klein et al. 2007).

Mainstreaming adaptation can lead to "no-regrets" opportunities to improve health systems now, regardless of the severity of climate impacts, and help reduce vulnerabilities to future climate and non-climate shocks (Watts et al. 2015). This will increase the likelihood of achieving development goals that are resilient to climate impacts and support the livelihoods of the most vulnerable groups of people (Ayers and Huq 2009). Examples of such actions benefiting the health system regardless of how many climate hazards materialize are many and include strengthening surveillance and response to vector-borne infectious diseases, training more medical staff, and introducing efficiency mechanisms to provide higherquality patient care.

In 2015, the World Health Organization launched a framework to embed adaptation in health services, to be used by nongovernmental organizations (NGOs), health ministries, and funding agencies. This framework was a response to growing demand from countries for guidance on how to operationalize and effectively address climate challenges in the health sector (WHO 2015a). It consists of six reinforcing building blocks to increase climate resilience across 10 components. These blocks are leadership and governance; health workforce; health information systems; essential medical products and technologies; service delivery; and financing (WHO 2015a; see Figure 3). Despite some gaps such as clear linkages 
between building blocks and how to prioritize them, the framework is easy to adapt to various contexts and captures the key aspects of health systems (Yoon 2020).

The WHO has also built on the UNFCCC's technical guidelines for drafting National Adaptation Plans to guide the development of Health-NAPs (WHO 2021). The goal of these "H-NAPs" is to strengthen and protect health systems from climate change, taking into account the biological, social, and physical determinants of health (Ebi and Villalobos Prats 2015). The H-NAP guidance outlines a systemic process by which countries can identify national goals and priority activities to build health resilience. It offers principles for cross-sectoral integration of health and climate change into national strategies, processes, and monitoring systems, and encourages pilot approaches (Ebi and Villalobos Prats 2015). A few countries have begun to develop pilots based on the guidelines. These include small island nations that are part of the Pacific Islands Action Plan on Climate Change and Health initiative (2019-2023), as well as Ethiopia through its Federal Ministry of Health's National Health Adaptation Plan to Climate Change (2018-2020) (FMH 2018). Kiribati, Chile, and Brazil have also developed a climate change and health strategy or sectoral plan (Savage et al. forthcoming).

In addition to mainstreaming adaptation into plans and policies, the gap between planning and on-theground implementation must also be addressed. This implementation gap can exist due to a variety of factors. Mogelgaard et al. (2018) demonstrated that adaptation is more likely to be mainstreamed across sectors and from the national to the local level-and the implementation gap is thus more likely to be closed-if five factors work together:

\section{Supportive policy frameworks}

Leadership from within and outside the government to drive the mainstreaming process

Coordination mechanisms that allow actors to cooperate across sectors and government departments to attain common mainstreaming goals

Information, monitoring, and evaluation frameworks and tools that enable learning
Finances to implement action (other authors have also noted the importance of increased finance to implement climate change adaptation activities-see UNEP 2021; Lebel et al. 2012; Olhoff et al. 2016; Caravani et al. 2017)

Although limited information on the costs of adaptation action exists, recognizing and assessing the many benefits of adaptation action for the health sector can help mobilize finance. Health co-benefits are rarely reflected in current NDCs: Only 3 percent of NDCs (5 out of 184) do so (WHO 2019a). The monetary benefits of preventing climate-related health impacts can be substantial, as illustrated by one study of the economic cost-benefit ratios for heatwave early warning systems in three European

Figure 3 | The WHO's Operational Framework for Building Climate Resilient Health Systems, with Six Building Blocks Supporting 10 Key Components of Health Systems

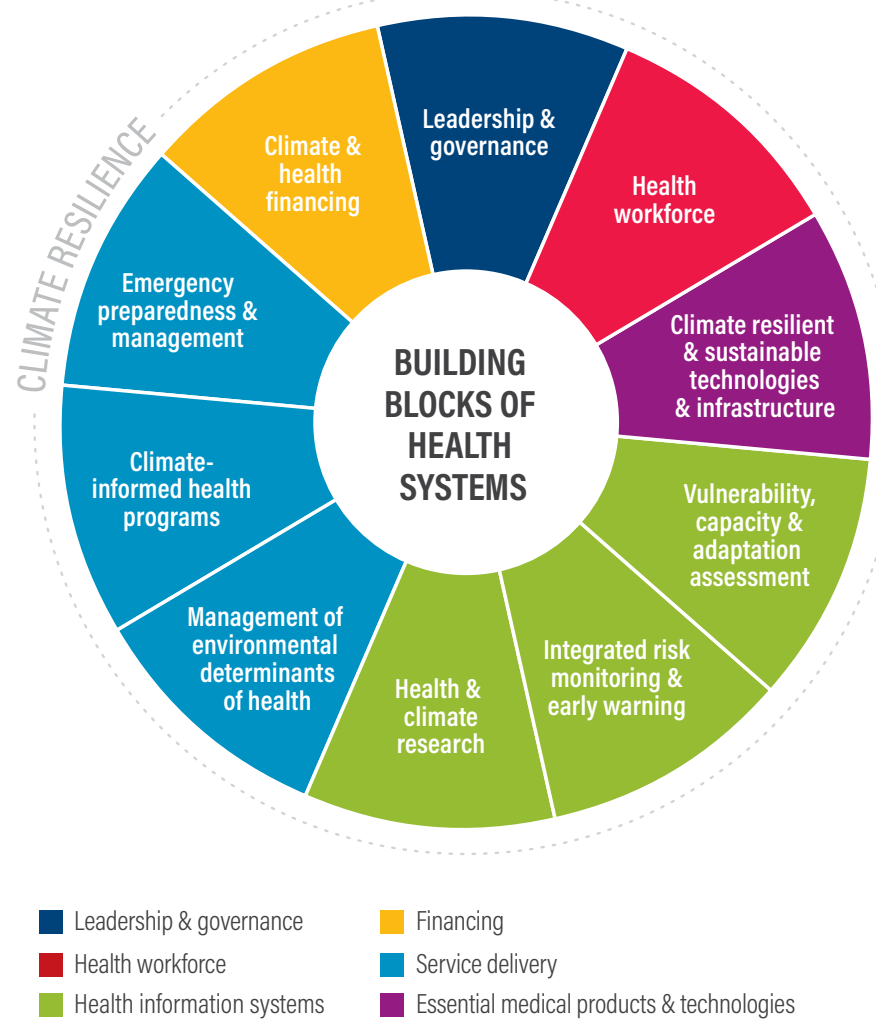

Note: WHO stands for World Health Organization.

Source: Adapted from WHO 2015a. 
cities (Hunt et al. 2016). Based on an economic model, with certain assumptions, this study found monetary benefits over a period of 50 years in Madrid ranging between $€ 2$ and $€ 4.7$ billion in savings across future climate scenarios. Similarly, Prague's savings were calculated to range between $€ 400$ and $€ 600$ million, while preventive measures in London could lead to savings ranging from $€ 54.6$ to $€ 154.2$ billion (Hunt et al. 2016). This analysis demonstrates that the benefits of adapting to current and future climate impacts to save lives and reduce the burden on health systems can be very high and can outweigh the costs of doing so-and are therefore to be considered no- or low-regrets options. Infrastructure improvements to health facilities like hospitals and clinics to enhance resilience are expensive but also cost-effective because they minimize or avoid costly emergency repairs and reduce service interruptions when climate hazards, like hurricanes, materialize (HCWH 2011). Strengthening the overall health system and increasing access could also result in equity co-benefits by especially benefiting groups that are traditionally marginalized.

For these impressive benefits to be realized, countries must move from merely planning to mainstream adaptation into their health systems to actually implementing such actions. This paper describes how three countries-Fiji, Ghana, and Benin-have not only designed programs and plans to mainstream adaptation into their health systems but also begun to move from planning to implementation on the ground.

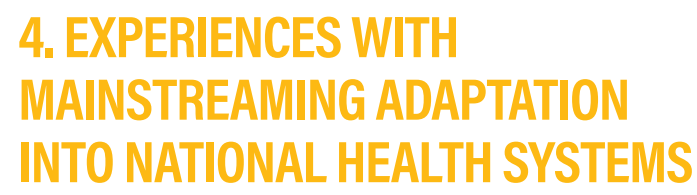

\subsection{Fiji}

\subsubsection{Health and climate change context and adaptation response}

Fiji is one of the most climate-vulnerable countries in the world, ranking $75^{\text {th }}$ out of 181 countries in the ND-GAIN Country Index (ND-GAIN 2018). As an island nation with many people living in low-lying areas, it grapples not only with sea level rise but also with devastating cyclones, floods, and droughts (GoF et al. 2018). With rising temperatures and increasing rainfall in certain areas of Fiji, threats-such as higher incidences of vector-borne diseases like dengue fever and water-borne illnesses like diarrhea, and the impact on noncommunicable diseases including cardiovascular and respiratory illnesses-must be addressed (GoF et al. 2018). Droughts, which lower the availability and quality of water needed to maintain health and hygiene, also threaten some parts of Fiji.

Fiji is mainstreaming adaptation into its health system and implementing adaptation and health activities through not only technical support provided by external sources but also its own government resources, particularly those from the Ministry of Health (see Figure 4). Essential to this progress is the Climate Change and Health Strategic Action Plan (CCHSAP) 2016-2020, which incorporates climate adaptation through the 10 components of the WHO's Operational Framework for Building Climate Resilient Health Systems, depicted in Figure 3 (MoHMS 2016). In 2020, the CCHSAP was extended for another two years and a new plan will be in place by 2023 .

The expected results from adaptation and health activities in the CCHSAP include an increased ability to provide and use reliable information on the occurrence of climatesensitive health risks by establishing an early warning system; greater capacity of health sector institutions to respond to these risks; and piloting disease prevention measures in higher-risk areas (WHO n.d.).

The "Piloting Climate Change Adaptation to Protect Human Health" project of the Ministry of Health and Medical Services (MoHMS)-which aimed to enhance the ability of the health system to respond effectively to climate-sensitive diseases-paved the way for the creation of the CCHSAP. Between 2010 and 2015, the project was implemented in 10 vulnerable sites across Ba and Suva cities (located in the west and east of Fiji, respectively, and with a combined population of about 342,000 ) with support from the WHO, Fiji Red Cross Society, and the United Nations Development Programme (UNDP). The four-year project was funded by the Global Environment Facility (GEF), which implemented versions of the pilot in seven countries globally. The lessons learned from the pilot-which include how to build a "climate-resilient health system" based on electronic medical records, how to climate-proof hospitals, and the need to prioritize vulnerable groups and remote communities for health equity (GoF 2018)-have been incorporated into the CCHSAP. 
Through the project, health officials in the pilot communities strengthened their technical capacity to report on disease outbreaks using geo-location of lab results to trace those infected. Sufficient field practitioners were trained to carry out this work (WHO n.d.). As a result of the pilot, the pilot communities now have adaptation strategies in place to improve the quality of drinking water. The project also led to an increase in construction of water tanks. These water tanks can help prevent water-borne diseases, which will become more prevalent as climate change causes more droughts and floods. The project also led to the establishment of the Climate Change and Health Unit in the MoHMS, charged with implementing health and adaptation activities both at the national level as well as in support of local communities.

Following the development of the CCHSAP, Fiji received a grant for $\$ 6$ million from the Korea International Cooperation Agency to build and integrate climateresilient health systems over a three-year period, 2019-2021 (WHO 2017). This project includes raising awareness of and building capacity for adaptation and disease prevention. Since 2015, the government of Fiji has also received the WHO's support for health officials and stakeholders to participate in key government climate change meetings and UNFCCC processes as a member of a multi-country working group to implement the Pacific Islands Action Plan on Climate Change and Health (WHO $2019 \mathrm{~b}$ ). One objective of this informal working group is to build climate-resilient health systems in all Pacific Island nations and areas by 2030, which includes the creation of action roadmaps through national Health-NAPs.

\subsubsection{Key enabling factors in mainstreaming} adaptation into the health system

National and regional commitments prioritize health and adaptation linkages. Several national and regional dialogues and declarations to mainstream climate risk into health generated momentum that led the MoHMS to formulate the CCHSAP in 2014 and keep this topic a priority item, commencing in 2015. These include convenings prioritizing health and climate actions such as the 2009 Pacific Health Ministers Meeting, the 2015 Suva Declaration on Climate Change, the 2015 Yanuca Island Declaration of Pacific Health Ministers Meeting, and the

Figure 4 | Policy Landscape for Integrating Climate Adaptation into Fiji's Health System

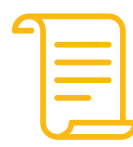

Integration into

policies and plans

- Climate Change and Health

Strategic Action Plan (CCHSAP)

- Roadmap for Democracy and

Sustainable Socio-Economic

Development (2010-2014)

- Green Growth Framework (2014)

- National Climate Change Policy

(2019-2030)

- National Adaptation Plan (NAP)

- National Development Plans

(NDP 2017-2021; 2017-2036)

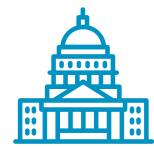

Political

leadership

- Permanent Secretaries of the

Ministry of Health, who also

encouraged cross-sectoral

collaboration

- Climate Change and Health Unit

(Ministry of Health)

- Climate Change Health Steering

Committee for the CCHSAP

- Participation in the Pacific Islands Action Plan on

Climate Change and Health

Working Group

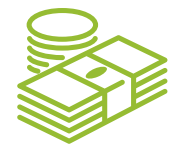

Funding mechanisms in place

- Fiji has received external funding to carry out pilot projects

- Domestic funding for the Ministry of Health

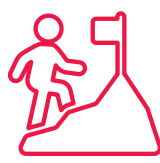

Challenges

- Insufficient finance

- Technical capacity, including to understand climate and health linkages

Source: Authors. 
2015 KAILA! Pacific Voice for Action on Agenda 2030. The Roadmap for Democracy and Sustainable SocioEconomic Development (2010-2014) discusses climate impacts on health, and the Green Growth Framework includes a section on health (2014). Climate-specific national commitments that Fiji has endorsed, such as its National Climate Change Policy (2019-2030) and NAP, also call for mainstreaming climate change adaptation into health planning and actions.

Recognizing that a "healthy population is a resilient population," Fiji's NAP includes a section on health with 10 priority actions to improve health systems and infrastructure to manage future climate variability (GoF 2018). These actions are largely drawn from the CCHSAP and feature ongoing activities as well those planned for the next five years. They also align with other national plans and documents, like the National Development Plan and the Disaster Risk Reduction Policy. Ongoing actions include the following:

Establishing formal links, under the guidance of the Climate Change Health Steering Committee and Health Advisory Working Group, to incorporate the health agenda into national and regional platforms

- Ensuring coordinated risk management for climate-related health risks

- Strengthening partnerships with key ministries including the Fiji Meteorological Service

- Retrofitting infrastructure and equipment to withstand climate impacts, using the Guidelines for Climate Resilient and Environmentally Sustainable Health Care Facilities in Fiji

- Developing the capacities of health workers (including technicians and doctors) related to climate adaptation and disaster risk reduction (GoF 2018)

Health leaders champion mainstreaming adaptation into health planning. According to interviewees, permanent secretaries in the health sector (among them Drs. Salanieta Saketa, Metuisela Tuicakau, and Eloni Tora) played an important role in mainstreaming climate change adaptation into health planning. They advocated for a climate change focus in the health system from the start of the pilot project. They chaired the pilot project's inter-ministerial Steering Committee and played a strong advocacy role in integrating climate adaptation into health policies and implementing key actions. They promoted this approach both within and beyond the health sector, even after their terms ended. The permanent secretaries encouraged stakeholder engagement and collaboration among MoHMS, UNDP, the WHO, the Fiji Meteorological Service, the Water Authority of Fiji, the Fiji Climate Change Division, and Fiji National University. The collaboration centered around the design and key components of CCHSAP. The discussions benefited from the recommendations that came out of the pilot project.

Increased knowledge regarding the climate sensitivity of health policies facilitates on-the-ground action and leads to additional financial and human resources. A key lesson learned from the pilot project was the importance of identifying climate-sensitive linkages in the current health portfolio and incorporating these connections into the regular training program for health staff. According to an in-country health and climate expert, the CCHSAP helped strengthen clean water and vector control programs that were already in place, increased knowledge of climate-health linkages, and changed staff behaviors to improve climate readiness. This expert stated that while the connection between seasonal weather and diseases has been clear to environmental health officials from the beginning, other health officials throughout Fiji have now received training to better understand these linkages, and that this improved understanding has helped the health sector acquire more financial and human resources to implement activities.

Figure 5 highlights the main enabling factors that emerged in Fiji to help close the gap between planning and action.

\subsubsection{Challenges to mainstreaming}

The challenges in Fiji's case are related to technical capacity, building a common understanding, and finance. Interviewees indicated that officials struggle with establishing and understanding the nonlinear causality between the effects of climate change on health, which is still an evolving field, and developing stronger policy interventions. For example, difficulties exist in differentiating additional diarrheal mortality caused by climate change from the existing cases, according to a WHO interviewee involved with the pilot project. This made it difficult for Fijian authorities to assess-based on the pilot project alone-what should be included or omitted from the CCHSAP. This challenge highlights the need for health officials to have access to good quality data and guidance on how climate risk impacts health outcomes. 


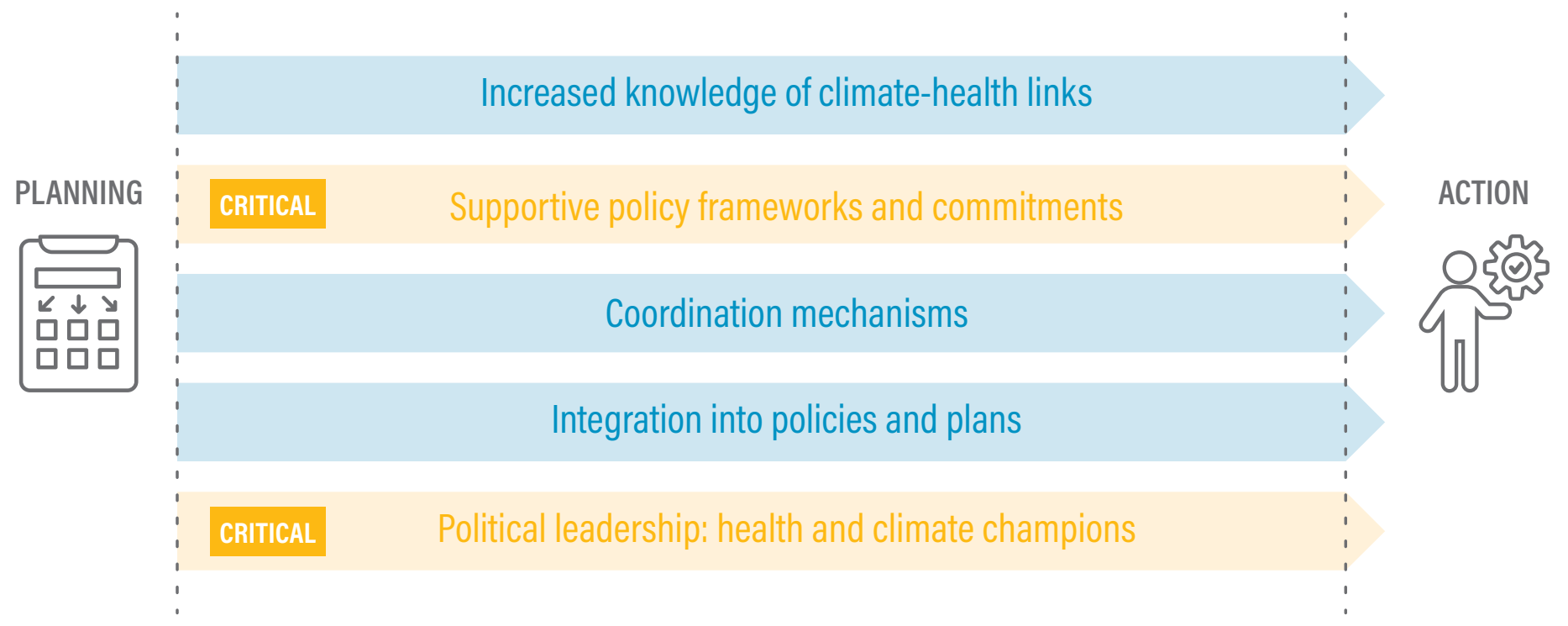

Note: Mogelgaard et al. (2018) describe in "From Planning to Action: Mainstreaming Climate Change Adaptation into Development" how different "gears," working together, can accelerate the closing of the implementation gap. The weight of each gear as well as the presence of each element may differ in each country context. Our preliminary assessment is that supportive policies and commitments, alongside political leadership, have been critical in moving from planning to action on the ground in Fiji.

Source: Authors,

Experts interviewed shared that their efforts to acquire feedback from government ministries, UNDP, the WHO, the Fiji Meteorological Service, the Water Authority, the national Climate Change and Health Unit, and others on the proposed CCHSAP required substantive engagement with key decision-makers to ensure consensus and understanding. Fortunately, engagement was made easier by coordinating through the multisectoral Steering Committee of the pilot project. The campaign to socialize the report revealed the challenges of soliciting feedback from people with different technical perspectives-that is from both health as well as climate adaptation expertsbut the consistent and vocal support from high ministerial champions bolstered momentum until the CCHSAP was complete.

Another challenge is the limited availability of financial data and funding; the percentage of allocated, available public climate funds for health in 2016-19 was limited to approximately 0.58 percent of total climate finance, and data regarding the rate of disbursement of these funds are lacking (FME 2020).

\subsection{Ghana}

4.2.1 Health and climate change context and adaptation response

Ghana is experiencing increasing temperatures, changing rainfall patterns, and higher risks of drought and storms. Water quality and quantity are also projected to be negatively impacted (RCNG 2019). Ghana ranks 109th out of 181 countries in the ND-GAIN Country Index (NDGAIN 2018).

The country's climate impacts have important implications for public health, as they can trigger or worsen diseases prevalent in the country, particularly cholera, diarrhea, malaria, and meningitis. In addition, climate events can complicate the delivery of health care and exacerbate poor sanitation and urban flooding problems, placing further pressure on the health system's limited facilities and budgets. Climate shocks and hazards also heighten malnutrition and household hunger by adversely affecting agriculture (Cooper et al. 2019). 
Ghana has taken initial steps to increase institutional and technical capacities to tackle climate change and health and build the climate resilience of health infrastructure (WHO 2015b). These include governance and policy measures like a government-approved national health adaptation strategy, and the implementation of programs and projects such as including climate information and early warning systems for climate-sensitive health risks in the Integrated Disease Surveillance and Response system (WHO 2015b).

To address the impacts of climate change on health, the Ministry of Health, with funding from the GEF and UNDP, implemented the Climate Health Ghana Project in 2010. This pilot project, which ended in 2015, helped mainstream climate risks into the health sector, including through policies like the Health Sector Medium Term Development Plans for 2010-13 and later 2014-17, where the strategy included the need to find appropriate responses to climate-induced disease patterns (UNDP n.d.). Mainstreaming climate into health issues is incorporated in other policies and strategies as well, as shown in Figure 6.
The project implemented adaptation measures in three districts: Keta, Gomoa West/Apam, and Bongo. The first two are located in southern Ghana and the third near the northern border, and in 2010 their populations were approximately $65,000,135,000$, and 84,500 , respectively (GSS 2020). In these districts, the public health sector mapped climate hazard areas, set up health screening tools, helped climate-vulnerable communities establish emergency centers to report on climate impacts like flooding that could lead to health hazards, and trained over 750 health workers and community volunteers on how to respond during climate and other emergencies.

The project also established cross-sectoral coordination strategies to support mainstreaming climate adaptation into national and local health policies and plans (UNDP 2014). Even though a lack of funding is currently preventing these efforts from continuing or scaling at the ministerial level after the project ended in 2015, according to experts interviewed, communities in the three districts

Figure 6 | Policy Landscape for Integrating Climate Adaptation into Ghana's Health System

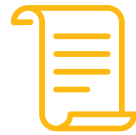

Integration into policies and plans

- National Climate Change
Adaptation Strategy
- National Climate Change Policy
(NCCP)
- Ghana National Climate Change
Master Action Programmes for
Implementation (2015-2020)
- Ghana Shared Growth and
Development Agenda (2014-2017)
- Integrated Disease Surveillance
and Response system

- National Climate Change Adaptation Strategy

- National Climate Change Policy and Response system

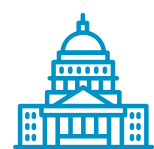

Political leadership

\section{- Inter-ministerial National Climate Change Committee, which included the Ministry of Health and the Ghana Health Service}

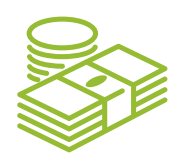

\section{Funding mechanisms} in place

- Ghana has received external funding to carry out projects

- It is unclear to what extent domestic funding exists for climate and health, although plans to earmark such budgets have been outlined (e.g., see Asante et al. 2015)

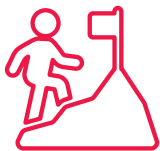

Challenges

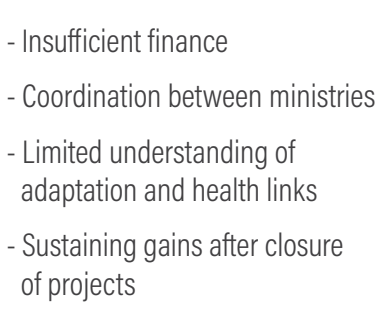

- Coordination between ministries

- Limited understanding of

Sustaining gains after closure

Source: Authors. 
continue to implement these activities, and some neighboring districts have even begun adopting similar measures. However, without strengthening climate change and health leadership and governance structures at all levels of the health system, or dedicated funding to finance integrated public health activities, it will be difficult for Ghana to sustain results and expand efforts.

\subsubsection{Key enabling factors in mainstreaming adaptation into the health system}

Policy frameworks are in place to guide how climate adaptation is mainstreamed into the health system. Climate action has gained momentum in Ghana, and adaptation to climate change is being mainstreamed into national development frameworks like the Ghana Shared Growth and Development Agenda (2014-2017). In 2012, Ghana released its National Climate Change Adaptation Strategy (2015-2020), which advocated for increasing knowledge of climate change issues in the health sector and featured concrete actions for adaptation priorities in health across eight action programs. The actions included their estimated costs and the ministries responsible for implementing them. Examples of activities are the establishment of a research center on climate change and health, and integration of inter-institutional environment and health surveillance systems via standardized tools and protocols (RoG 2015).

A year later, Ghana launched its National Climate Change Policy (NCCP), produced under the guidance of the inter-ministerial National Climate Change Committee, which included the Ministry of Health and the Ghana Health Service (MESTI 2013). The NCCP detailed the required policy actions and identified program focus areas to mainstream climate risks into the health sector, and estimated that 10 percent of the Ministry of Health's annual spending, or $\$ 94$ million, should be budgeted for climate-related actions (Asante et al. 2015). The subsequent Ghana National Climate Change Master Plan Action Programmes for Implementation (2015-2020) include health as a priority area, acknowledging the growing importance of linking the country's health status with the effects of climate change. The priority of the health sector was yet again confirmed in Ghana's National Adaptation Plan Framework (EPA 2018).

The Master Plan Action programs include specific healthrelated objectives, actions, and timelines; associated responsible entities; and estimated costs. The programs emphasize increasing the capacity of health providers to improve data management and data storage, and reinforcing the links between climate change and health (MESTI 2015). They also note the need to strengthen the capacity of groups working on climate change issues; increase climate-related health research; enhance climatesensitive disease surveillance; improve emergency health preparedness; increase intersectoral collaboration for better nutrition; and improve water quality and sanitation (MESTI 2015). In 2015-16, the Ministry of Health, Ghana Meteorological Agency, and Noguchi Memorial Institute for Medical Research conducted a Health Vulnerability and Adaptation Assessment to determine a vulnerability baseline and communities' adaptive capacities. This pilot assessment of three districts found positive relationships between climate variables and incidences of disease (e.g., malaria and rainfall, malaria and poverty) and data gaps due, in part, to nonfunctional weather stations (Asante and Bawakyillenuo n.d.).

Strong leadership and participation of community health workers and volunteers in pilot districts were instrumental in implementing on-the-ground activities. The interagency climate change committees established through the Climate Health Ghana Project pilot project in 2013 were made up of traditional leaders and youth, as well as community-based organizations and volunteer groups. According to interviewees, these committees were champions in influencing policies. They played an important role in raising awareness about the links between climate change and health at the national and local levels. The committee members were dedicated to on-the-ground implementation of district plans in coordinating action, trainings, and awareness-raising efforts. Their attention to these issues led to increased understanding of how climate change is affecting health infrastructure and systems at the local level.

Distribution of supplies and information enabled planning for and responding to climate hazards. Alongside raising awareness of climate risks and increasing training on how to respond to extreme weather events and other climate emergencies, Ghana's public health sector has provided essential supplies and communication to pilot communities. An initiative of the Climate Change and Health project, supported by UNDP and the GEF, provided mobile phones to doctors and nurses in the three pilot districts to quickly communicate and analyze health threats, trained 180 disease surveillance volunteers, and 
established free oral rehydration therapy centers across the region; in the town of Keta, for example, 11 health centers and six community health facilities received mobile communication resources (UNDP 2014).

Figure 7 highlights the main enabling factors that emerged in Ghana to help close the gap between planning and action.

\subsubsection{Challenges to mainstreaming}

Ghana's health sector faces coordination, finance, and information challenges. Although there has been progress coordinating policies at the national level, significant sectoral policy inconsistencies still exist, in part due to a limited understanding of the link between adaptation and health. This has resulted in some policies that are not aligned with each other, because ministries do not coordinate on cross-sectoral issues such as climate change. Although there is growing recognition of climate risks, these are still not properly mainstreamed into health sector plans, programs, and policies-particularly at the subnational level. Another challenge is ensuring that mainstreaming climate and health remains a priority after changes in administrations, which occur every few years.
Last, insufficient funding is an obstacle to implementing adaptation and health activities due in part to lack of data and technical expertise to inform sectoral budgets; most sectors, including health, therefore do not budget for climate change activities when presenting their annual plans to parliamentary hearings for approval, resulting in little to no climate finance. Drastic government funding cuts across sectors in the last decade limit available funding even further.

\subsection{Benin}

\subsubsection{Health and climate change context and adaptation response}

Benin has one of the highest rates of poverty worldwide, ranking 165 th out of 189 countries in the Human Development Index. The nation ranks 15oth out of 181 countries in the ND-GAIN Country Index, meaning it is highly vulnerable and its readiness level to address climate change is low (ND-GAIN 2018). Benin is vulnerable to climate change risks that can affect human health: floods, droughts, violent rains, heat waves, and strong winds, as well as sea level rise in the coastal zones and sandstorms in the extreme north of the country (GoB

\section{Figure 7 | Closing the Adaptation Planning and Implementation Gap in Ghana}

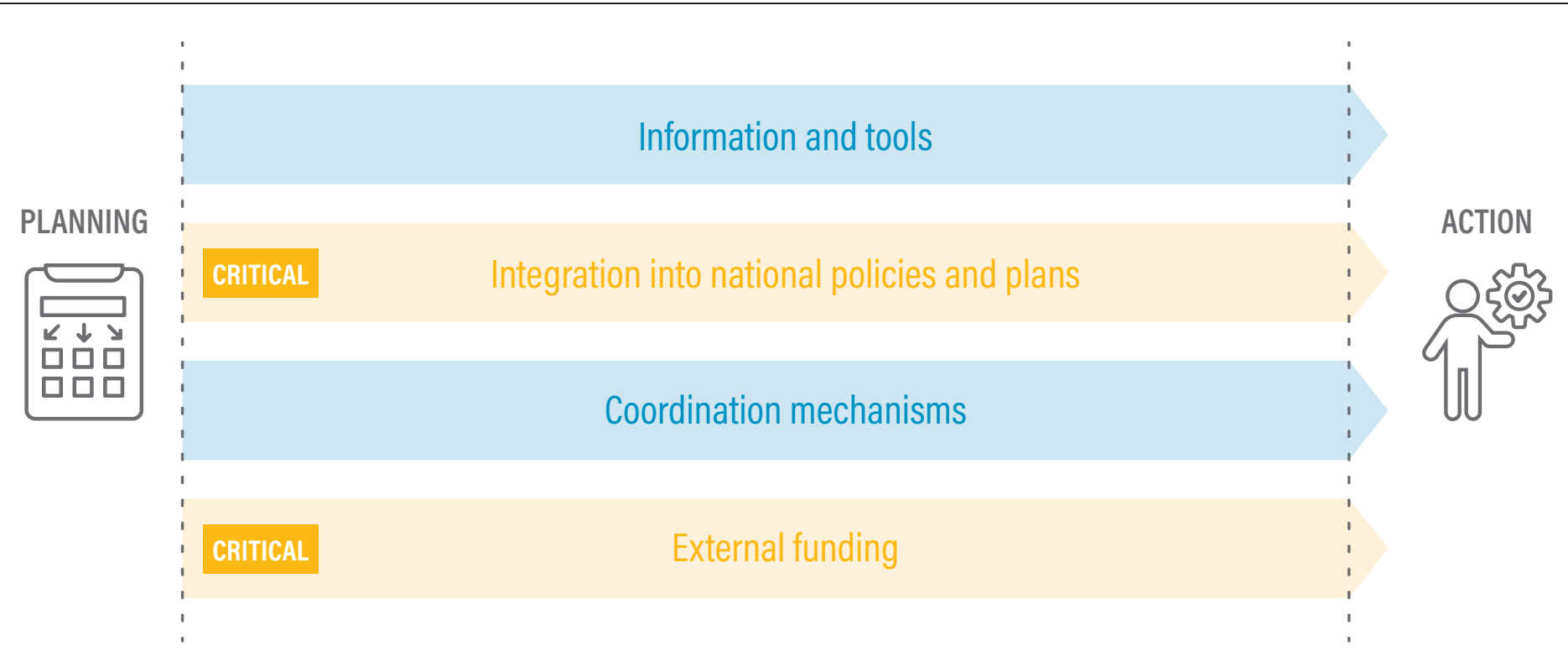

Note: Mogelgaard et al. (2018) describe in "From Planning to Action: Mainstreaming Climate Change Adaptation into Development" how different "gears," working together, can accelerate the closing of the implementation gap. The weight of each gear as well as the presence of each element may differ in each country context. Our preliminary assessment is that both integration into national policies and plans and external funding have been critical in moving from planning to action on the ground in Ghana.

Source: Authors. 
2019). Even though Benin is at the initial stages of implementing adaptation actions in its health systemmore so than Fiji-it has conducted promising pilot initiatives, established ministerial environmental cells, and committed politically in other ways to mainstream climate risks into the health system-for example, by commissioning vulnerability studies (see Figure 8).

The Beninese minister for social well-being and sustainable development refers in his introductory note to the Third National Communication to the UNFCCC to increased vulnerability levels, which made his government decide to include-for the first time-the health sector as a priority in its national communication to UNFCCC. A recent study commissioned by the Ministry of Health outlines that, in addition to malaria, which is the key disease emerging as being linked to the effects of climate change, respiratory diseases, diarrhea, typhoid fever, and Buruli ulcers are also highly climate-sensitive (MSB 2017).

The demand for health services in Benin is driven by infectious diseases; in fact, malaria is the main reason for primary health clinic visits (43.6 percent in 2016). Statistics show that malaria caused 14.9 percent of all deaths and was responsible for 23.4 percent of child mortality in 2016 (MSB 2016). Research in three municipalities in the southwest of Benin commissioned by the government reveals that malaria rates are expected to rise due to increased humidity levels and a higher average temperature. This research concludes that an increased prevalence of other infectious diseases is also likely (Akponikpe et al. 2019).

\subsubsection{Key enabling factors in mainstreaming adaptation into the health system}

The national commitment to health and climate adaptation emphasizes mainstreaming adaptation. Benin's Third National Communication on Climate Change stresses the importance of mainstreaming climate change adaptation into sectoral policies. It identifies the health sector as one of the seven key sectors for adaptation mainstreaming (MCV 2018). This echoes Benin's National Adaptation Programme of Action (2008), which names health as one of six sectors highly impacted by climate change, and Benin's NDC, which references the need for training health practitioners on climate impacts and establishing a monitoring and information

Figure 8 | Policy Landscape for Integrating Climate Adaptation into Benin's Health System

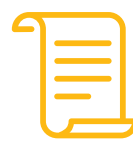

Integration into

policies and plans

- Third National Communication to the UNFCCC (2018)

- National Health Development Plan (2009-2018)

- National Adaptation Programme of Action (2008)

- NAP (forthcoming)

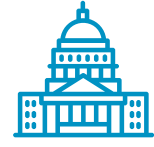

Political

leadership

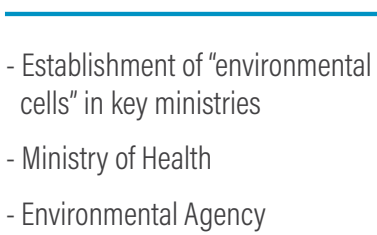

- Establishment of "environmental cells in key ministries

- Environmental Agency

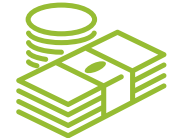

Funding mechanisms in place

- The Finance Ministry is expected to start integrating adaptation in its budget cycle

External support from the UN to local communities via the Local Climate Adaptive Living Facility

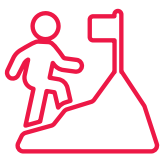

Challenges

- Insufficient public and external finance

- Climate risk management and data capacities

- Sustaining gains after closure of projects

Note: Abbreviations: NAP: National Adaptation Plan; UNFCC: United Nations Framework Convention on Climate Change; UN: United Nations. Source: Authors. 
system on climate impacts (GoB 2008; 2017). Benin's NAP, which was aimed for completion in 2020, will also feature human health as one of seven critical and vulnerable sectors (UNDP 2019). In the National Health Development Plan (2009-2018), the Beninese Ministry of Health calls for accelerated mainstreaming of climate change and assigns this responsibility to the health sector's leadership and management (MSB 2018). The country has also taken initial steps to better understand climate change impacts on health at the subnational level: In 2017, the government commissioned a study to analyze the consequences of climate change on the prevalence of infectious diseases, as well as a report that outlines each municipality's climate-related vulnerabilities in the health sector (MSB 2017).

\section{The establishment of ministerial "environmental cells" paves the way for mainstreaming}

adaptation. One way these commitments to mainstream adaptation into health policy and planning has started to translate into concrete action is through the government's creation of environmental cells, or units, in all key ministries, beginning in 2001. The cells are established focal points for environmental issues, including climate, within different ministries (among them health). The units are under the technical and financial supervision of the Benin Environmental Agency and are tasked with mainstreaming climate change into sectoral policies, planning documents, and projects (GIZ 2019). The cells foster strong intersectoral coordination and have led to the development of vulnerability studies, which have identified impact chains, adaptation options, and future vulnerabilities (GIZ 2019). At the request of the Beninese government, since 2016 the German Agency for International Cooperation has been providing technical assistance and training to strengthen the capacity of the environmental cells and to support sectoral ministries as they incorporate climate adaptation.

In the health sector, the environmental cell contributed to mainstreaming climate change into the 2018-2022 National Health Development Plan, which allowed the ministry to identify important indicators and to strengthen the country's health policies. In addition, the Ministry of Economy and Finance is expected to start integrating adaptation into its budget cycle, and an initial budget allocation may be included in the budget proposal to Parliament.
Benin is taking additional first steps to implement climate adaptation policies in the health sector. Strengthening research and analytical capacity was one of the first steps to mainstreaming climate adaptation into health sector policies and planning. Training is ongoing and several academic institutions in the West Africa region are involved (GoB 2019).

Initiatives like the United Nations Capital Development Fund's Local Climate Adaptive Living Facilitywhich is available in Benin through the Ministry of Environment and the Ministry of Decentralizationoffer local communities the opportunity to apply for financial support to cover the costs of making existing infrastructure or new projects resilient to the effects of climate change. Financial support is critical in Benin because primary health care centers depend on fee-based revenues, which much of the population currently cannot afford to pay. The authorities realize that without such external support from the UN, these centers will be unable to cover the costs to adapt health service delivery to the effects of climate change (MCV 2018).

Adaptation in the health sector must focus on physical infrastructure as well. The expected upsurge in infectious diseases raises questions such as whether there are enough primary health care centers and if their capacities are sufficient, and how to make health infrastructure resilient to extreme weather conditions. For example, the southwestern region of Benin will likely require additional health care facilities as the incidence of malaria increases due to higher humidity and warmer temperatures. In addition, the United Nations Children's Fund (UNICEF) provided solar-powered refrigerators to keep vaccines cool as temperatures increase; additional support along these lines will be needed.

Figure 9 highlights the main enabling factors that emerged in Benin to help close the gap between planning and action.

\subsubsection{Challenges to mainstreaming}

The challenges that have surfaced in Benin are related to finance, capacity, and governance. Despite the strong commitments, establishment of coordination mechanisms, and additional steps made toward improving the resilience of the health care system, Benin's budgetary constraints 


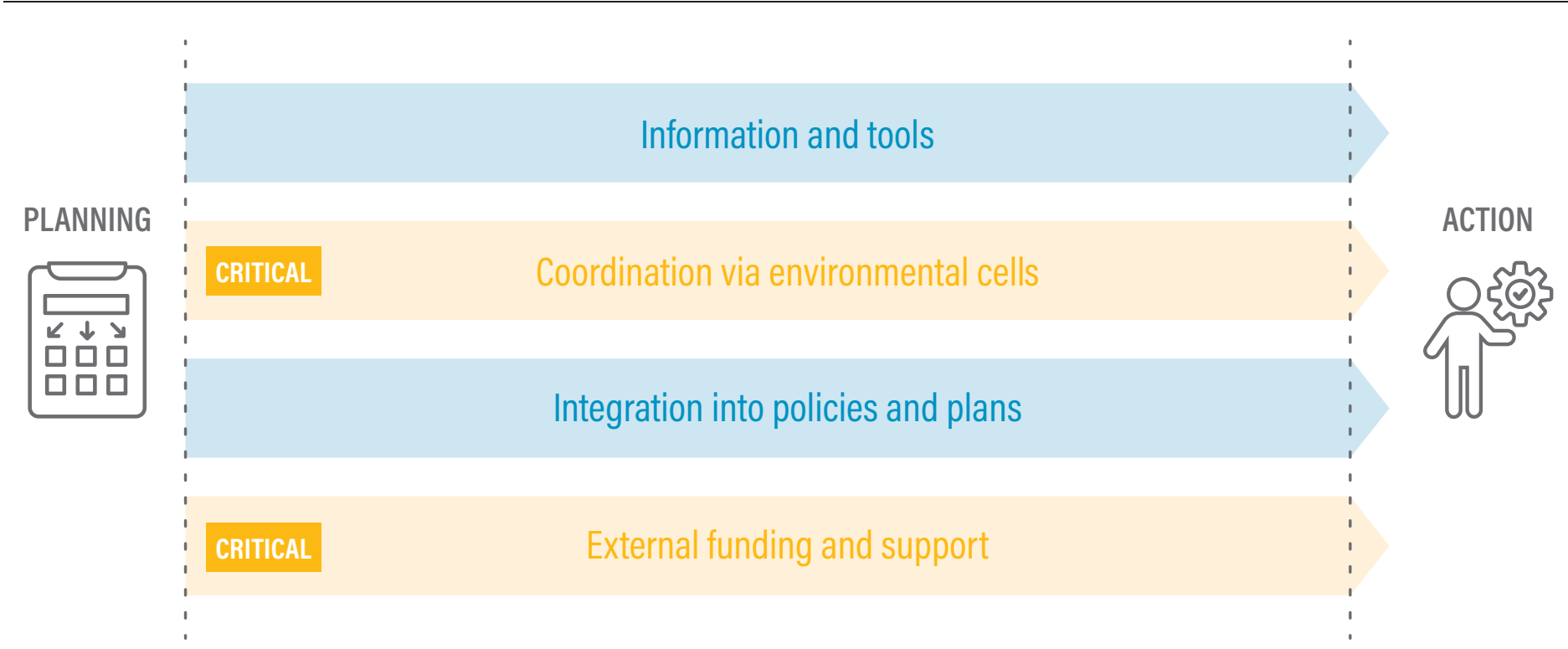

Note: Mogelgaard et al. (2018) describe in "From Planning to Action: Mainstreaming Climate Change Adaptation into Development" how different "gears," working together, can accelerate the closing of the implementation gap. The weight of each gear as well as the presence of each element may differ in each country context. Our preliminary assessment is that inter-ministerial coordination and external funding and support have been critical in moving from planning to action on the ground in Benin.

Source: Authors.

have slowed down action. Insufficient external funding is a related challenge: Benin's status as a least developed country indicates its need for external support. The fact that documentation from global climate funds, such as the Green Climate Fund, is mostly in English creates additional challenges in accessing finance.

Inadequate capacity to understand and manage climate risks is an overall challenge Benin faces. Support is needed to continue strengthening the knowledge of key players in the health sector, including municipal- and communitylevel leadership, given their critical role in overseeing the functioning of health care delivery at decentralized levels. Capacity for disease surveillance and in translating key data to easily understandable and up-to-date information is a related challenge.

Frequent changes in political leadership (regular changes in ministerial positions) may undermine the consistency required to ensure that the allocation of the scarce public resources is sufficient to mainstream climate adaptation into the health sector.

\section{LESSONS LEARNED ON MAINSTREAMING ADAPTATION IN FIJI, GHANA, AND BENIN}

This section brings together common factors that have advanced or hindered progress toward mainstreaming adaptation into the health care systems of Fiji, Ghana, and Benin, so that other countries that find their situations echoed in these countries may apply these lessons to achieve success and inspire greater action on this urgent issue, despite challenges.

\subsection{Common Key Enabling Factors in the Three Countries}

One key factor common to Fiji, Ghana, and Benin is having supportive policy frameworks and national-level communications in place to increase adaptation mainstreaming and raise awareness of climate and health linkages.

In Fiji and Ghana, line agencies have been able to come together around climate change and health to formulate policies that support future implementation of adaptation and health activities. 
In Fiji, a combination of national, regional, and international commitments led to mainstreaming adaptation into the health sector and the formulation of the Climate Change and Health Strategic Action Plan (CCHSAP). The CCHSAP, which has been extended until 2022 and will be subject to an evaluation, will likely continue to foster the implementation of adaptation and health activities.

- In Ghana, adaptation has been mainstreamed into national development plans and a national health strategy, and health concerns have been mainstreamed into national climate change policies, making this a priority for the entire government.

Similarly, Benin emphasizes the importance of mainstreaming climate risks into the health sector in its Third National Communication and has commissioned national studies and analyses to understand climate-related health risks and vulnerabilities.

\section{Continued political leadership and enthusiastic} champions for adaptation action are also key factors noted in each case study.

Fiji's permanent secretaries for health were crucial in shining a spotlight on climate change and health and pushing these issues forward, and in formulating the CCHSAP.

Interagency committees in Ghana connected nationaland local-level actors to inform policy and implement adaptation and health activities in and beyond the pilot sites. These committees raised awareness of the links between climate change and health. Community leaders and health professionals from the pilot districts also proved essential for effectively implementing adaptation activities.

- In Benin, the establishment of environmental cells in key ministries is playing an important role in mainstreaming adaptation in ministries, where this issue had not always been a priority.

All three countries also benefited to different degrees from pilot projects that jump-started the process of enabling and propelling adaptation action in the health sector. In all three countries, these pilots received critical external funding from international financial streams; at the same time, the authors did not see credible evidence that efforts were sustained after the pilot activity had been finalized, especially in the case of Ghana.
In Fiji, the "Piloting Climate Change Adaptation to Protect Human Health" project spurred mainstreaming and informed policies and plans on adaptation and health. Lessons learned from the project included enhancing the climate resilience of hospital infrastructure and prioritizing vulnerable groups and remote communities to improve equity in access to health care. Each lesson was incorporated into the $\mathrm{CCH}-$ SAP as key activities that the plan (which has been extended for another two years) will implement across Fiji.

The Climate Health Ghana Project strengthened the health resilience of three districts and long-term outcomes by gaining the buy-in of communities and training hundreds of volunteers and health officials. It also informed national-level plans.

In Benin's case, the nation benefited from several smaller pilot projects that helped raise awareness of climate and health linkages. These pilots have begun to demonstrate how to build infrastructural resilience and inspired concrete adaptation actions such as training of health staff.

\subsection{Common Challenges}

The three countries face technical challenges with mainstreaming climate adaptation into health policies, which could affect the extent to which adaptation and health measures are implemented at the local level and therefore how much the implementation gap can be closed.

The lack of a strong understanding of the links between climate change and adaptation is present in all three cases. In Fiji, technical questions on whether a disease outbreak was due to climate change or not needed to be addressed before the CCHSAP could be formulated. The linkages are clearer to environmental health and public health officers who observe how disease patterns shift with the weather, but less so with other officials (until they have received training). Ghanaian experts interviewed discussed how this knowledge gap can lead to inconsistent sectoral policies where adaptation and health may not align. 
In Ghana, technical challenges related to availability and access to data hampered planning, making it unclear where and how to target climate-vulnerable groups. Additionally, poor translation of technical terms to communities minimized their ability to understand the linkage between climate change and health.

Similarly, interviewees from Benin stressed the need for increased technical capacity, particularly for disease surveillance and making key data easier to understand.

Another challenge common to all three countries is inadequate finance to support implementation of adaptation and health activities.

In Ghana, there are limited human resources and skills to ensure that adaptation and health activities are adequately budgeted for when they are prepared and presented to Parliament.

\section{In Benin, frequent changes in administration} can make it difficult to ensure consistent allocation of public resources for adaptation in the health sector. In addition, international climate funds were reported to be challenging to access since application forms are sometimes not translated into French, making it difficult to apply for funding.

The previously mentioned technical challenge that Fiji faces in establishing the causality between climate and health is a barrier to developing successful proposals to obtain finance.

\section{RECOMMENDATIONS}

The experiences of Fiji, Ghana, and Benin indicate five key recommendations for how countries-especially those with similar challenges and characteristics-can more quickly mainstream adaptation into health plans, policies, and projects, and start closing the implementation gap:

Policymakers can seize on the political momentum created by the global pandemic to strengthen their countries' abilities to respond to a range of shocks and stressors-including the linked challenges of infectious disease and climate change. The COVID-19 pandemic is shining a spotlight on the importance of robust and resilient health care systems that serve the needs of both the wealthy and people living in poverty. Strengthening the overall capacities and resources of health systems-e.g., building robust supply chains, increasing training of medical staff, retrofitting technology and equipment, and establishing protections against interrupted health services-will increase adaptive capacity to deal with climate impacts while providing many other benefits. Increasing human capacity and financial resources is paramount to ensuring that effective measures are taken to better manage rapidly mounting climate-related risks to health.

Governments should establish policy frameworks and collaboration mechanisms to provide needed guidance and support for mainstreaming climate adaptation in the health sector. The national processes for formulating National Adaptation Plans offer an excellent opportunity to advance mainstreaming. Mainstreaming climate adaptation in this sector is important given the growing impact of extreme weather patterns and events, shifts in vector-borne diseases, and other climate-related risks to the health of human populations. A clear national mandate to mainstream climate adaptation into sectoral plans and strategies underlines the importance of making an integrated approach a priority going forward. A whole-of-government approach to climate adaption is required, but this entails coordination at the highest levels of government. Providing incentives or a mandate to apply coordination mechanisms would help ensure that different ministries are sharing information and resources openly and efficiently, and working together to mitigate the impact of climate risks. 
Funders, including governments, should encourage and finance health pilot projects and use lessons from these experiences to inform climate resilience planning in health sector plans and policies. Pilot projects (as demonstrated by the Fiji and Benin cases) can pave the way for broader adaptation mainstreaming in the health sector and lead to cross-sectoral learning experiences. It is important to sustain the gains made through these pilots by integrating their outcomes into national and subnational projects, plans, and policies.

Ministries of Health and adaptation planners should jointly design and implement health plans and policies that mainstream climate adaptation and demonstrate their feasibility through on-the-ground projects; the National Adaptation Plan framework provides a process to make this happen. Greater collaboration between these two areas of expertise can strengthen policies and implementation plans. Effective climate adaptation in the health sector, which is often decentralized and must reflect the country and local context, requires strong links with primary health care facilities at the local level.

Champions of climate and health issues inside and outside of the health sector should be supported so they can continue to raise awareness and rally resources for action. The responsibility for adapting to climate change lies not just with Ministries of Health, which should take a leadership role, but also with representatives from relevant NGOs, academia, the private sector, and communities. A cross-cutting, cross-sectoral approach that draws upon political will and engages adaptation champions and key stakeholders, including subnational public and private actors, is needed to make health systems more resilient to climate change. These actors should be involved in planning and decision-making, for example, via interagency committees and coordinated efforts at local and regional levels. A combination of political will and cross-cutting coordination will be critical in driving implementation.

\section{CONCLUSION}

The cases presented in this paper illustrate that while Fiji, Ghana, and Benin are making progress on mainstreaming climate adaptation into their health care systems, these countries face critical challenges in scaling up promising pilot programs and closing the implementation gap. Given the lack of widespread evidence that countries are successfully addressing this pressing issue, and the link between building resilience to climate change impacts and the spread of infectious diseases like COVID-19, this area merits far more attention and support.

Despite the need for better data and improved access, enough information on climate-sensitive health risks exists to take critical no-regrets adaptation measures in the health sector now. Local data may not always be available, nor sufficient to prove causality with full certainty between climate risks and health, yet the linkages between climate change and health continue to grow in clarity and evidence. Climate impacts are already being felt in the health sector, and a lack of conclusive evidence does not justify ignoring potential risks (Watts et al. 2015). Climate impacts are expected to increase over time, further affecting mortality, morbidity, and productivity; creating additional burdens on already struggling health systems; and widening inequalities.

The urgency to protect people and the health system against climate-related health risks is clear-and is called for in national policies and international commitmentsyet funding to support greater on-the-ground action continues to lag. As being in the midst of the global COVID-19 pandemic reveals, it is imperative to strengthen health systems everywhere and build up their resilience against shocks.

Taking action now to enhance the resilience of the health system in the face of current and future climate impacts protects countries' hard-won development gains and helps put countries on a positive long-term trajectory. Effective adaptation can protect people's health and well-being, resulting in a more productive workforce and reducing the risks and costs of future climate impacts-especially in the face of uncertainty. 
APPENDIX A, GENERAL SEMI-STRUCTURED INTERVIEW OUESTIONS FOR COUNTRY EXPERTS

\section{Purpose of the Interview}

Mainstreaming adaptation entails integrating adaptation into development plans. In the mainstreaming process, relevant actors, private and public, proactively consider climate risks, vulnerabilities, and impacts in their policies and plans. Mainstreaming adaptation into development policies and plans could lead to the implementation of adaptation action.

The purpose of this questionnaire is to understand the process of mainstreaming adaptation. We aim to learn the enabling factors that have led to narrowing or closing the "implementation gap" as well as the barriers that slow down the process of mainstreaming. We also wish to better understand the benefits of mainstreaming.

\section{Section 1: Broad Questions}

1. Can you tell me briefly about your familiarity and experience with climate change and adaptation?

2. Do you think that integrating adaptation into sectoral plans, development policies, or other policy documents is important? Why or why not?

3. What level of adaptation planning would you say your country is at?

a. Incipient - just starting to think about adaptation planning

b. Early - e.g., funding and staffing for adaptation planning have been established

c. Intermediate - an adaptation plan, such as a National Adaptation Plan, is underway

d. Advanced - plans for adaptation have been established with concrete activities outlined

4. What stage of implementing adaptation would you say your country is at?

a. Incipient - just starting to think about integrating adaptation

b. Early - planning for integration of adaptation but no implementation yet

c. Intermediate - some implementation of adaptation planning in some sectors/ministries

d. Advanced - many sectors/ministries/programs are considering and implementing adaptation actions

5. Has your country been able to mainstream adaptation in the health, disaster risk reduction, agriculture, watersheds, and/or ecosystems fields? If so, how was adaptation mainstreamed?

\section{Section 2: Enabling Factors and Barriers to Mainstreaming Adaptation}

6. From this list of five topics (or "gears"), which are the two that really stand out as being enabling factors or barriers, and why? Interviewers can use the following gears to prompt additional details, e.g., if leadership is mentioned, you can ask the questions listed under Leadership.

a. Policy Framework:

i. Does your country have political commitments, mandates, and laws that support the integration of adaptation into health planning? If so, please describe them.

b. Leadership:

i. Are there leaders or champions positively influencing the mainstreaming of adaptation in your country? Who are they, what is their motivation, and what institution/sector do they represent?

ii. How have these leaders supported mainstreaming adaptation planning and how has this catalyzed action?

iii. Has training champions in health and climate helped to mainstream adaptation?

c. Coordination:

i. Has there been any cross-sector collaboration to mainstream adaptation?

ii. Have inter-ministerial steering committees, task forces, or discussions been set up to support mainstreaming?

d. Information and tools:

i. Is the Ministry of Health able to access and share data on climate-sensitive diseases and risks? Has this led to more health plans with climate information?

ii. Do health officials have access to planning tools that help mainstream adaptation into health systems?

e. Financial process:

i. Is there funding for decision-makers to consider climate risks in health planning?

7. Other:

a. Are there other enabling factors or barriers that you would like to highlight?

\section{Section 3: Implementation Stage and the Benefits of Main- streaming}

8. Now that you have mainstreamed adaptation, is this leading to the implementation of adaptation action? If so, what is being implemented?

9. Is the country gathering any data on the level of implementation or monitoring any outcomes from mainstreaming adaptation?

10. Has this implementation shown any benefits? If so, what are the benefits? If not, why not? 
1. Several indices exist to measure the level of vulnerability to climate change. These include the ND-GAIN Country Index, the Global Climate Risk Index, and Maplecroft's Climate Change Vulnerability Index. Indices use different methodologies, but they all come to roughly the same ranking of climate-vulnerable countries. The authors have used the ND-GAIN Country Index, composed of a vulnerability score and a readiness-to-improve resilience score, for this working paper. The vulnerability score measures a country's exposure, sensitivity, and ability to adapt to negative climate impacts by assessing vulnerability in six life-supporting sectors: food, water, ecosystem services, health, infrastructure, and human habitat (ND-GAIN 2018). Higher scores are better.
Akponikpe, P.B.I., P. Tovihoudji, B. Lokonon, E. Kpadonou, J. Amegnaglo, A.C. Segnon, R. Yegbemey, et al. 2019. Etude de Vulnérabilité Sectorielle face aux changements climatiques au Benin. [Sectoral Vulnerability Study in the face of climate change in Benin.] Berlin: Climate Analytics.

Asante, F.A., and N. Bawakyillenuo, n.d. Assessment of Existing Relevant Climate, Health, Poverty and Vulnerability Information. Accra, Ghana: Republic of Ghana, Ministry of Health, in partnership with the United Nations Development Programme and the Global Environment Facility, http://www. adaptation-undp.org/sites/default/files/downloads/ghana_national_climate_change_adaptation_strategy_nccas.pdf.

Asante, F.A., S. Bawakyillenuo, N. Bird, N. Canales Trujillo, C. Addoquaye Tagoe, and N. Ashiabi. 2015. Climate Change Finance in Ghana. London: Overseas Development Institute, and Accra, Ghana: Institute of Statistical, Social and Economic Research, University of Ghana. With the support of the Ministry of Finance, Government of Ghana. https://www.odi.org/sites/odi.org.uk/files/ odi-assets/publications-opinion-files/9684.pdf.

Caminade, C., K.M. Mclntyre, and A.E. Jones. 2019. "Impact of Recent and Future Climate Change on Vector-Borne Diseases." Annals of the New York Academy of Sciences 1436 (1): 157-73. https://doi.org/10.1111/nyas.13950.

Campbell-Lendrum, D., L. Manga, M. Bagayoko, and J. Sommerfeld. 2015. "Climate Change and Vector-Borne Diseases: What Are the Implications for Public Health Research and Policy?" Philosophical Transactions of the Royal Society of London. Series B, Biological Sciences 370: 1665. https://doi. org/10.1098/rstb.2013.0552.

Caravani, A., S. Greene, N. Canales Trujillo, and A. Amsalu. 2017. "Decentralising Climate Finance: Insights from Kenya and Ethiopia." BRACED Working Paper. London: BRACED. https://www.odi.org/sites/odi.org.uk/files/ re-source-documents/11804.pdf.

Chaudhury, M., T. Summerlin, and N. Ginoya. 2020. "Mainstreaming Climate Change Adaptation in Kenya: Lessons from Makueni and Wajir Counties." Working paper. Washington, DC: World Resources Institute. https://files. wri.org/s3fs-public/mainstreaming-climate-change-adaptation-kenya_1. pdf?yE_Svo4hTx4RUSCsfMoarOStmFWt5LGj.

Cooper, M., M.E. Brown, C. Azzarri, and R. Meinzen-Dick. 2019. "Hunger, Nutrition, and Precipitation: Evidence from Ghana and Bangladesh." Population and Environment 41: 151-208. https://doi.org/10.1007/s11111-019-00323-8.

Dinshaw, A., N. Ginoya, P. Preethan, A. Nambi Appadurai, and M. Gutiérrez Rivera. 2018. "Mainstreaming Adaptation in Action: Case Studies from Two States in India." Working Paper. Washington, DC: World Resources Institute. http://www.wri.org/publication/mainstreaming-adaptation-action. 
Dunne, D. 2020. "Mapped: How Climate Change Disproportionately Affects Women's Health." London: Carbon Brief. https://www.carbonbrief.org/ mapped-how-climate-change-disproportionately-affects-womens-health.

Ebi, K.L., and E. Villalobos Prats. 2015. "Health in National Climate Change Adaptation Planning." Annals of Global Health 81 (3): 418-26. D01: 10.1016/j. aogh.2015.07.001. https://www.ncbinlm.nih.gov/pmc/articles/PMC4697129/.

Ebi, K.L., P. Berry, D. Campbell-Lendrum, G. Cissé, J. Hess, N. Ogden, and R. Schnitter. 2019. "Health System Adaptation to Climate Variability and Change." Rotterdam and Washington, DC: Global Center on Adaptation. https://cdn.gca.org/assets/2019-12/HealthSystemAdaptationToClimateVariabilityandChange.pdf.

EPA (Environmental Protection Agency, Republic of Ghana). 2018. Ghana's National Adaptation Plan Framework. In partnership with the National Development Planning Commission and the Ministry of Finance, October. Accra, Ghana: EPA. https://napglobalnetwork.org/wp-content/uploads/2020/04/ napgn-en-2018-ghana-nap-framework.pdf.

FME (Fiji Ministry of Economy). 2020, "Fiji Climate Finance Snapshot: 20162019." Suva, Fiji: Government of Fiji. https://www.economy.gov.fj/images/ CCIC/uploads/ClimateFinance/Fiji-Climate-Finance-Snapshot-2016-2019.pdf.

FMH (Federal Ministry of Health, Government of Ethiopia). 2018. National Health Adaptation Plan to Climate Change (2018-2020). Addis Ababa, Ethiopia: Government of Ethiopia. https://www.who.int/globalchange/resources/ wash-toolkit/national-health-adaptation-plan-to-climate-change.pdf.

GIZ (Deutsche Gesellschaft für Internationale Zusammenarbeit; German Agency for International Cooperation). 2019. "Mainstreaming Climate Change Adaptation into Sectoral Planning: Learning from Benin's Environmental Cells." Transparency Partnership Good Practice Database. Bonn, Germany: GIZ. https://api.knack.com/v1/applications/5b23f04fd240aa37e01fa362/download/asset/5d08aafabld06e000dafd125/190603_gpd_parisabkommen_benin_01.pdf.

GoB (Government of Benin), 2008. "Programme d'action national d'adaptation aux changements climatiques du Benin (PANA-Benin)." ["National Adaptation Programme of Action (NAPA-Benin)."] Cotonou, Benin: GoB. https://www. adaptation-undp.org/sites/default/files/downloads/benin_napa.pdf.

GoB. 2017. Benin's First Nationally Determined Contribution under the Paris Agreement, Cotonou, Benin: Ministry of Living Conditions and Sustainable Development, GoB. https://www4.unfccc.int/sites/ndcstaging/PublishedDocuments/Benin\%20First/CDN_BENIN_VERSION_ANGLAISE.pdf.
GoB. 2019. Troisième Communication Nationale du Benin a la Convention Cadre des Nations Unies sur les Changements Climatiques. ["Benin's Third National Communication on Climate Change under the United Nations Framework Convention on Climate Change."] Cotonou, Benin: Government of Benin. https://unfccc.int/sites/default/files/resource/BENIN_TCN_2019.pdf.

GoF (Government of Fiji), World Bank, and Global Fund for Disaster Risk Reduction. 2018. Climate Vulnerability Assessment: Making Fiji Climate Resilient. Washington, DC: World Bank. https://www.gfdrr.org/sites/default/files/publication/Making\%20Fiji\%20Climate\%20Resilient\%20-\%20Full\%20Report.pdf.

GoF. 2018. Republic of Fiji National Adaptation Plan: A Pathway towards Climate Resilience. Suva, Fiji: Government of Fiji. https://www4.unfccc.int/sites/ NAPC/Documents/Parties/National\%20Adaptation\%20Plan_Fiji.pdf.

GSS (Ghana Statistical Services). 2020. "Ghana: Administrative Division. Regions and Districts." Census Data. Accra, Ghana: Ghana Statistical Services. https://www.citypopulation.de/en/ghana/admin/.

Gupta, J., and N. van der Grijp. 2010. Mainstreaming Climate Change in Development Cooperation: Theory, Practice and Implications for the European Union. London: Cambridge University Press.

HCWH (Health Care Without Harm). 2011. A Comprehensive Environmental Health Agenda for Hospitals and Health Systems around the World. Global Green and Healthy Hospitals Agenda. http://greenhospitals.net/wp-content/ uploads/2011/10/Global-Green-and-Healthy-Hospitals-Agenda.pdf.

HRC (United Nations Human Rights Council). 2018. "The Slow Onset Effects of Climate Change and Human Rights Protection for Cross-Border Migrants." 37th Session, February 26-March 23. Geneva: HRC.

Hunt, A., J. Ferguson, M. Baccini, P. Watkiss, and V. Kendrovski. 2016. "Climate and Weather Service Provision: Economic Appraisal of Adaptation to Health Impacts." Climate Services 7: 78-86. http://dx.doi.org/10.1016/j. cliser.2016.10.004.

IPCC (Intergovernmental Panel on Climate Change). 2014. Climate Change 2014: Synthesis Report. Contribution of Working Groups I, II and III to the Fifth Assessment Report of the Intergovernmental Panel on Climate Change. [Core Writing Team, R.K. Pachauri and L.A. Meyer (eds.)]. Geneva: IPCC. https:// www.ipcc.ch/site/assets/uploads/2018/02/SYR_AR5_FINAL_full.pdf.

Klein, R.J.T., S.E.H. Eriksen, L. Otto Næss, A. Hammill, T.M. Tanner, C. Robledo, and K.L. O'Brien. 2007. "Portfolio Screening to Support the Mainstreaming of Adaptation to Climate Change into Development Assistance." Climatic Change 84: 23-44. 
MCV (Ministère du Cadre de Vie et du Développement Durable, Benin; Ministry for Social Well-Being and Sustainable Development, Benin). 2018. "Version Provisoire: Chapitre 4: Vulnérabilité et adaptation aux changements climatiques." In Elaboration de la Troisième Communication Nationale du Benin sur les Changements Climatiques. ["Draft: Chapter 4: Vulnerability and adaptation to climate change." In Elaboration of Benin's Third National Communication on Climate Change.] Cotonou, Benin: Government of Benin.

MESTI (Ministry of Environment, Science, Technology and Innovation, Republic of Ghana). 2013. Ghana National Climate Change Policy. Under the guidance of the National Climate Change Committee. Accra, Ghana: MESTI. https://www.un-page.org/files/public/ghanaclimatechangepolicy.pdf.

MESTI. 2015. Ghana National Climate Change Master Plan Action Programmes for Implementation: 2015-2020. Accra, Ghana: MESTI. https://www.weadapt. org/sites/weadapt.org/files/2017/ghana_national_climate_change_master_plan_2015_2020.pdf.

Mogelgaard, K., A. Dinshaw, N. Ginoya, M. Gutiérrez, P. Preethan, and J. Waslander. 2018. "From Planning to Action: Mainstreaming Climate Change Adaptation into Development." Working Paper. Washington, DC: World Resources Institute. https://www.wri.org/ publication/climate-planning-to-action.

MoHMS (Ministry of Health and Medical Services, Fiji), 2016. Climate Change and Health Strategic Action Plan 2016-2020. Suva, Fiji: MoHMS.

MSB (Ministère de la Santé du Bénin; Benin Ministry of Health). 2016. "Annuaire des Statistiques Sanitaires." ["Annual Health Statistics."] Cotonou, Benin: Government of Benin. Page 163.

MSB. 2017. "Rapport Provisoire: Analyse de la vulnérabilité et de l'adaptation du secteur santé au changement climatique au Bénin." ["Draft: Vulnerability and adaptation analysis of the health sector in the face of climate change in Benin."] Cotonou, Benin: Government of Benin. Page 17.

MSB. 2018. Plan National de Developpement Sanitaire, 2018-2022. [National Health Development Plan, 2018-2022]. Cotonou, Benin: Government of Benin. https://www.prb.org/wp-content/uploads/2020/06/Benin-Plan-National-de-D\%C3\%A9veloppement-Sanitaire-2018-2022.pdf.

NDC Partnership. 2020. Adaptation and NDCs: From Analysis and Planning to Action and Ambition Raising. Washington, DC, and Bonn, Germany: NDC Partnership. https://ndcpartnership.org/sites/default/files/Extended_Report-Adaptation_and_NDCs_From_Analysis_and_Planning_to_Action_and_Ambition_Raising_October-2020.pdf.

ND-GAIN (Notre Dame-Global Adaptation Initiative). 2018. "Rankings." NDGAIN Country Index, https://gain.nd.edu/our-work/country-index/rankings/.
Olhoff, A., B. Dickson, D. Puig, K. Alverson, and S. Bee. 2016. The Adaptation Finance Gap Report. Copenhagen: United Nations Environment Programme and DTU.

RCNG (Resource Centre Network Ghana). 2019. "The Impact of Climate Change on Water Quality." https://www.washghana.net/node/78.

RoG (Republic of Ghana). 2015. Ghana National Climate Change Master Plan Action Programmes for Implementation: 2015-2020. Accra, Ghana: Ministry of Environment, Science, Technology and Innovation, Republic of Ghana via weADAPT. https://www.weadapt.org/knowledge-base/national-adaptation-planning/ghana-national-climate-change-policy-action-programme.

Savage, A., E. Villalobos Prats, D. Campbell-Lendrum, A. Dazé, J. Dekens, and C. Corvalan. Forthcoming. "Review: Health in National Adaptation Plans." Geneva: World Health Organization.

Speranza, J., F. Maschietto, L.C. Costa, and V.E. de Oliveira. 2018. Assessment of the Limits, Challenges, and Opportunities for Adaptation Mainstreaming in Brazilian Cities. Washington, DC: World Resources Institute.

Tye, S., J. Waslander, and M. Chaudhury. "Building Coastal Resilience in Bangladesh, the Philippines, and Colombia: Country Experiences with Mainstreaming Climate Adaptation." Working Paper. Washington, DC: World Resources Institute. https://files.wri.org/s3fs-public/building-coastal-resilience-bangladesh-philippines-colombia_0.pdf?A0arkUTKBMMPfHxJqg4x1NimGad7bDuB.

UN (United Nations). 2019. "Only One in Five Countries Has a Healthcare Strategy to Deal with Climate Change." UN News, https://news.un.org/en/ story/2019/12/1052631.

UNDP (United Nations Development Programme), n.d. "Integrating Climate Change into the Management of Priority Health Risks in Ghana: Key Results and Outputs." https://www.adaptation-undp.org/projects/sccf-health-ghana.

UNDP. 2014. "Project Saves Keta from Cholera This Year." https://www.adaptation-undp.org/projects/sccf-health-ghana.

UNDP. 2019. "Benin Scales Up Preparations for Climate Change, Advancing Its National Adaptation Plan." https://www.adaptation-undp.org/ benin-scales-preparations-climate-change-advancing-its-national-adaptation-plan.

UNEP (United Nations Environment Programme). 2021. Adaptation Gap Report 2020. Nairobi: UNEP. https://www.unenvironment.org/resources/adaptation-gap-report-2020. 
Voita, T, and S. Morton. 2020. "NDP Partnership: Health in NDCs." NDC Partnership Insight Brief. Washington, DC, and Bonn, Germany: NDC Partnership. https://ndcpartnership.org/sites/default/files/Insight_Brief-Health_in_ NDCs_0ctober-2020.pdf.

Watts, N., W.N. Adger, P. Agnolucci, J. Blackstock, P. Byass, W. Cai, S. Chaytor, et al. 2015. "Health and Climate Change: Policy Responses to Protect Human Health." The Lancet 386: 1861-1914. https://gahp.net/wp-content/ uploads/2017/10/Health-and-climate-change-policy-responses-to-protectpublic-health.pdf.

WHO (World Health Organization). n.d. Climate Change Adaptation to Protect Human Health: Fiji.

Geneva: WHO. https://www.who.int/docs/default-source/climate-change/ adaptation-report-fiji-2010.pdf?sfvrsn=80d3b127_2.

WH0. 2015a. Operational Framework for Building Climate Resilient Health Systems. Geneva: WHO. https://apps.who.int/iris/bitstream/handle/10665/189951/9789241565073_eng.pdf?sequence=1.

WH0. 2015b. Climate and Health Country Profile: Ghana. Geneva: WHO. https://apps.who.int/iris/bitstream/handle/10665/208862/WHO_FWC_PHE_ EPE_15.08_eng.pdf?sequence $=1$.

WH0. 2017. Pacific Island Countries and Areas-WHO Cooperation Strategy 2018-2022. https://www.who.int/westernpacific/about/how-we-work/pacific-support/pacific-health-ministers-meetings

WH0. 2018a. COP24 Special Report: Health and Climate Change. Geneva: WHO. https://apps.who.int/iris/bitstream/handle/10665/276405/9789241514972eng.pdf?ua=1.

WH0. 2018b. "Climate Change and Health." https://www.who.int/news-room/ fact-sheets/detail/climate-change-and-health.

WH0. 2019a. WHO Review: Health in the NDCs. Geneva: WHO. https://www. who.int/docs/default-source/climate-change/health-in-ndcs---a-who-review. pdf?sfvrsn=43b6b2c6_1.

WH0. 2019b. Meeting of the Informal Working Group to Discuss the Implementation of the Pacific Islands Action Plan on Climate Change and Health (2019-2023). Meeting Report. Suva, Fiji: WHO. https://apps.who.int/iris/bitstream/handle/10665/331928/RS-2019-GE-21-FI-eng.pdf.

WH0. 2021. Quality Criteria for Health National Adaptation Plans. Geneva: WHO. https://www.who.int/publications/i/item/quality-criteria-health-national-adaptation-plans.
WRI (World Resources Institute). 2018. The GCF's Approach to Adaptation: Analysis and Implications for the Fund. Addendum to the Green Climate Fund Meeting of the Board, October 17-20, 2018. https://www.greenclimate.fund/ document/gcf-b21-inf03-add01.

Yoon, S. 2020. "How to Build Climate Resilient Health Systems: Reinforce the Framework Instead of Re-inventing the Wheel." Sushruta Journal of Health Policy \& Opinion 13 (2). DOl: 10.38192/13.2.1. 


\section{ACKNOWLEDGMENTS}

We are pleased to acknowledge our institutional strategic partners that provide core funding to WRI: the Netherlands Ministry of Foreign Affairs, Royal Danish Ministry of Foreign Affairs, and Swedish International Development Cooperation Agency.

We are also pleased to acknowledge our funder, the Federal Ministry for Economic Cooperation and Development of Germany (BMZ). BMZ has provided generous support to carry out research for this working paper as a contribution to the NDC Partnership. The authors would like to thank all the respondents and country case interviewees who provided rich information for this paper. We are grateful to our reviewers, Sam Bickersteth, Chen Chen, Abiyot Dagne Belay, Angie Dazé, Pamil Deka, Ayesha Dinshaw, Teodyl Nkuintchua, Kelera Oli, Liz Saccoccia, Ayushi Trivedi, and Crystal Upperman for their helpful feedback. We would also like to thank Rebecca Carter for her guidance during the year-long process of research, writing, and revisions.

\section{ABOUT THE AUTHORS}

Stefanie Tye is a research associate with the Climate Resilience Practice at WRI. She works on a range of projects, including transformative adaptation in the agriculture sector, mainstreaming adaptation, and providing countries with technical assistance on strengthening climate resilience.

Contact: stye@wri.org

Jacob Waslander is a senior associate at WRI. He works on cross-cutting issues (relating to climate action, in particular climate finance and sustainable investing) in the Governance Center, the Finance Center, the Climate Program, and the NDC Partnership.

Contact: jwaslander@wri.org

\section{ABOUT WRI}

World Resources Institute is a global research organization that turns big ideas into action at the nexus of environment, economic opportunity, and human well-being.

\section{Our Challenge}

Natural resources are at the foundation of economic opportunity and human wellbeing. But today, we are depleting Earth's resources at rates that are not sustainable, endangering economies and people's lives. People depend on clean water, fertile land, healthy forests, and a stable climate. Livable cities and clean energy are essential for a sustainable planet. We must address these urgent, global challenges this decade.

\section{Our Vision}

We envision an equitable and prosperous planet driven by the wise management of natural resources. We aspire to create a world where the actions of government, business, and communities combine to eliminate poverty and sustain the natural environment for all people.

\section{Our Approach}

\section{COUNT IT}

We start with data. We conduct independent research and draw on the latest technology to develop new insights and recommendations. Our rigorous analysis identifies risks, unveils opportunities, and informs smart strategies. We focus our efforts on influential and emerging economies where the future of sustainability will be determined.

\section{CHANGE IT}

We use our research to influence government policies, business strategies, and civil society action. We test projects with communities, companies, and government agencies to build a strong evidence base. Then, we work with partners to deliver change on the ground that alleviates poverty and strengthens society. We hold ourselves accountable to ensure our outcomes will be bold and enduring.

\section{SCALE IT}

We don't think small. Once tested, we work with partners to adopt and expand our efforts regionally and globally. We engage with decision-makers to carry out our ideas and elevate our impact. We measure success through government and business actions that improve people's lives and sustain a healthy environment.

ccreative Copyright 2021 World Resources Institute. This work is licensed under the Creative Commons Attribution 4.0 International License

cc) commons (1) To view a copy of the license, visit http://creativecommons.org/licenses/by/4.0/ 